Regina Aparecida Segatto Saiani

\title{
Concentração de chumbo em dentes de crianças com alterações neurológicas
}

Orientadora: Profa. Dra. Raquel Fernanda Gerlach 
Regina Aparecida Segatto Saiani

\section{Concentração de chumbo em dentes de críanças com alterações neurológicas}

Tese apresentada à Faculdade de Odontologia de Ribeirão Preto, da Universidade de São Paulo, para a obtenção do grau de Doutor em Ciências, área de Odontopediatria.

Orientadora: Profa. Dra. Raquel Fernanda Gerlach 
Saiani, Regina Aparecida Segatto Concentração de chumbo em dentes de crianças com alterações neurológicas. Ribeirão Preto, 2012.

95p. : il. ; $30 \mathrm{~cm}$

Tese de Doutorado, apresentada à Faculdade de Odontologia de Ribeirão Preto/USP. Área de concentração: Odontopediatria.

Orientador: Raquel Fernanda Gerlach.

1. Dentes. 2. Esmalte dental. 3. Chumbo. 4. Alterações neurológicas. 
Regina Aparecida Segatto Saiani

\section{Concentração de chumbo em dentes de}

\section{crianças com alteraçöes neurológicas}

Tese apresentada à Faculdade de Odontologia de Ribeirão Preto, da Universidade de São Paulo, para a obtenção do grau de Doutor em Ciências, área de Odontopediatria.

Aprovado em:

Banca Examinadora

\begin{tabular}{|c|c|}
\hline \multicolumn{2}{|l|}{ Prof. Dr.: } \\
\hline Julgamento: & Assinatura: \\
\hline \multicolumn{2}{|l|}{ Prof. Dr.: } \\
\hline Julgamento: & Assinatura: \\
\hline \multicolumn{2}{|l|}{ Prof. Dr.: } \\
\hline Julgamento: & Assinatura: \\
\hline \multicolumn{2}{|l|}{ Prof. Dr.: } \\
\hline Julgamento: & Assinatura: \\
\hline \multicolumn{2}{|l|}{ Prof. Dr.: } \\
\hline Julgamento: & Assinatura: \\
\hline
\end{tabular}




\section{Dados Currículares}

Regina Aparecida Segatto Saiani

Nascimento

04/04/1965

Filiação

Osmar Apparecido Saiani

Maria Regina Segatto Saiani

1986 - 1990 Graduação em Odontologia

Universidade de Uberaba - UNIUBE

1998 - $2000 \quad$ Especialização em Odontopediatria

Universidade de Ribeirão Preto - UNAERP

2005 - $2007 \quad$ Mestrado

Faculdade de Odontologia de Ribeirão Preto da Universidade de São Paulo - FORP/USP

2008 - $2012 \quad$ Doutorado

Faculdade de Odontologia de Ribeirão Preto da Universidade de São Paulo - FORP/USP 
Não está na natureza das coisas que o homem realize um descobrimento sibito inesperado; a ciência avança passo a passo e cada homem depende do trabalho de seus predecessores. (Ernest Rutherford) 


\section{Dedico este trabalho}

Aos meus fithos Matheus e Mariana, minha maior fonte de amor e inspiração, essa vitóría não é minha, ela é nossa. Agradeço todos os dias, a nossa grande mãe natureza pelo privilégio de, nessa vida, ser mãe de vocês. Foi, é e será sempre uma grande aventura.

Euamovocês.

"Filho é um ser que nos emprestaram para um curso intensivo de como amar alguém além de nós mesmos, de como mudar nossos piores defeitos para darmos os melhores exemplos e de aprendermos a ter coragem. Isto mesmo! Ser pai ou mãe é o maior ato de coragem que alguém pode ter, porque é se expor a todo tipo de dor, principalmente da incerteza de estar agindo corretamente e do medo de perder algo tão amado. Perder? Como? Não é nosso, recordam-se?

Foi apenas um empréstimo."

(José Saramago) 


\section{Dedico este trabalho}

Ao mew irmão Osmar, o nosso Osmarzinho para a familia um artista, talvez especial por ser comóé, assim, autista.

"Crianças são como borboletas ao vento... algumas voam rápido... algumas voam pausadamente, mas todas voam do seu melhor jeito... Cada uma é diferente, cada uma é linda e cada uma é especial." (poema de uma criança especial da APAE)

Tu te tornas eternamente responsável por aquilo que cativas. (Antoine de Saint-Exupéry) 


\section{Agradecimentos Especiais}

A toda minha famitia, em especial aos meus pais Osmar $e$ Regina, meus idolos, exemplos de retidão e vida. Seres humanos especiais que, com muita simplicidade, carinho e amor, sempre me ensinaram tudo aquilo que realmente importa na vida.

Aos meus irmãos Andréa, Rogéría, Fabiana, Luciano e Osmarzinho pelo apoio nos momentos mais dificeis da minha vida, pela união e pelo respeito, pela solidariedade e amizade. Não somos só irmãos de sangue, somos também irmãos de coração.

Ao meu companheiro e amigo Beto pelo incentivo, pela paciéncia, pelo amor, por todos os ensinamentos a mim conferidos nestes últimos dez anos, por caminhar ao meu lado mesmo quando não se faz presente. Obrígada amor.

Aos meus cunhados Paulo, Beto e Juliana pelos anos de convivência e por acrescentar pontos nesta minha evolução.

porque o essencial é invisivel aos olhos, só se vê bem com o coração.

(Antoine de Saint-Exupéry) 


\section{Emespecial..}

A minha orientadora Profa. Dra. Raquel Fernanda Gerlach você fez parte do meu processo de amadurecimento, que apesar de muitas vezes ser doloroso, me rendew frutos maravithosos. Dentre eles, a sua amizade com certeza está entre os que mais valorizo. Ew não saberia expressar com palauras $\sigma$ meu carinho e admiração. Obrigada pela oportunidade de reatizar um sonho.

A Profa. Dra. Carolina A. R. Funayama agradeço a Deus por tê-la conhecido, e por ter sido orientada durante estes últimos meses por você. Obrigada pela paciência, disposição, ternura e bom-humor com os quais você sempre me tratou. Obrigada pelos ensinamentos. Você mora dentro do meu coração. Para sempre!

"Foi o tempo que investiste em tua rosa que a fizeste tão importante." (Antoine de Saint-Exupéry) 


\section{Agradecimentos}

Aos ambulatórios da área de Neurologia do HCFMRP-USP: Neurologia Infantil Geral, sob a coordenação da Profa. Dra. Carolina A. R. Funayama e de Epütepsia Infantil, sob a coordenação da Profa. Dra. Regina Maria França Fernandes por me permitirem realizar a coleta de minhas amostras.

Aos docentes do Departamento de Clinica Infantil, Odontologia Preventiva e Social da Faculdade de Odontologia de Ribeirão Preto da Universidade de São Paulo, Profa. Dra. Lea Assed Bezerra da Silva, Profa. Dra. Aldevina Campos de Freitas, Profa. Dra. Maria Cristina Borsatto, Profa. Dra. Kranya Victoria Díaz Serrano, Prof. Dr. Pauto Nelson Fitho, Profa. Dra. Alexandra Mussolino de Queiroz, Profa. Dra. Maria Conceição Pereira Saraiva, Prof. Dr. Adilson Thomazinho, Prof. Dr. José Tarcisio Lima Ferreira, Profa. Dra. MirianAiko Nakame Matsumoto, Profa. Dra. Maria Bernadete Sasso Stuani, Profa. Dra. Raquel Assed Bezerra da Silva, Profa. Dra. Sada Assed, Profa. Dra. Andiara De Rossi pelas orientações e ensinamentos.

Aos colegas de Doutorado em Odontopediatría da Faculdade de Odontologia de Rúbeirão Preto da Universidade de São Paulo, Carolina Paes Torres Mantovani, Cristhiane Ristum Bagatin Rossi, Cristiane Tomaz Rocha, Fabricio Kitazono Carvalho, Jaciara Miranda Gomes da Silva, Maristela Soares Swerts Pereira, Rodrigo Teixeira Macri, Soraya Cheier Díb Gonçalves, pela agradável convivência. 
Aos funcionários do Departamento de Clinica Infantil, Odontologia Preventiva e Social da Faculdade de Odontologia de Ribeirão Preto da Universidade de São Paulo, Carmo Eurípedes Terra Barreto, Dorival Gaspar, Fátima Aparecida Jacinto Daniel, Fátima Aparecida Rizóli, Filomena Leli Placciti, Marco Antônio dos Santos, Micheli Cristina Leite Rovanholo, Renata Aparecida Fernandes Rodrigues, Matheus Morelli Zanela, Francisco Wanderley Garcia de Paula e Silva e Carolina Paes Torres Mantovani. Obrigada pela dedicação.

A Faculdade de Odontologia de Rúbeirão Preto da Universidade de São Pauto, no nome do atual Diretor Prof. Dr. Valdemar Mallet da Rocha Barros.

A Coordenação do Curso de Pós-Graduação em Odontopediatría da Faculdade de Odontologia de Rúbeirão Preto da Universidade de São Paulo, na pessoa da Profa. Dra. Lea Assed Bezerra da Sílva, pela oportunidade de ser aluna deste programa.

As funcionárías da Seção de Pós-Graduação da Faculdade de Odontologia de Rúbeirão Preto da Universidade de São Paulo, Isabel Cristina Gatino Sola e Regiane Cristina Moi Sacilotto, pelo carinho e atenção.

A Carolina de Souza Guerra pela agradável convivência, e pela ajuda na parte experimental deste trabalho. Pessoa dedicada, sempre pronta a ajudar. Obrigada, Carol, pelo sen bom-humor! 
A Profa. Dra. Márcia Andréa Mesquita Silva da Veiga e Flávio Venâncio Nakadi do Departamento de Química da Faculdade de Filosofia, Ciências e Letras de Ribeirão Preto pelas análises de chumbo.

A Karina Alessandra M. Grecca Pieroni e Soraya Cheier Dí Gonçalves pelo auxilio na coleta das amostras e pelo incentivo durante a fase experimental.

Ao Prof. Geraldo Cássio dos Reis pelas sugestóes e auxítio na elaboração da análise estatistica e pela atenção com que sempre me receben.

Ao Prof. Dr. Rafael Rosales, pelas sugestões e auxilio na elaboração da fórmula matemática.

À Prefeitura de Sertãozinho, em especial ao coordenador de Sauide Bucal Dr. Paulo Síqueira, por ter sido compreensivo e por ter me dado tanto apoio nos preparativos finais deste trabalho.

Aos mens amigos e colegas de trabalho Aline, Ana Cláudia, Ana Márcia, Daniela Lataro, Daniela, Danilo, Devanir, Gülber,Gustavo, Elis, Janaina, Marley, Michele, Rose, Sérgio, Tereza, Toninha, Yosdani pelo incentivo.

A todos que, de alguma forma, contribuiram para a concretização dessa pesquisa. Muito Obrigada!

O destino não é freqüentemente inevitável, mas uma questão de escolha. Quem faz escolhas, escreve sua própria história, constrói seus próprios caminhos.

(autor desconhecido) 


\section{Resumo}

Saiani, RAS. Concentração de chumbo em dentes de crianças com alterações neurológicas [dissertação]. Ribeirão Preto: Faculdade de Odontologia de Ribeirão Preto da Universidade de São Paulo; 2012.

Introdução: A exposição ambiental ao chumbo é uma questão séria do ponto de vista de saúde pública, pois quando ocorre nos primeiros meses e anos de vida pode levar a sequelas neurológicas e comportamentais graves.

Objetivos: 1- Determinar a concentração de chumbo obtida por meio de microbiópsias de esmalte realizadas in vivo em esmalte de dentes permanentes ou decíduos de pacientes com problemas neurológicos em tratamento ambulatorial no HCFMRP-USP e comparar os resultados em diferentes grupos de acordo com o diagnóstico. 2- Verificar o perfil dos valores de chumbo segundo informações relacionadas à exposição a esse metal dos referidos pacientes.

Método: Uma microbiópsia foi realizada in vivo na superfície do esmalte de crianças de 5 a 12 anos, de ambos os gêneros, atendidas sequencialmente, sem conhecimento sobre a doença, em dois ambulatórios da área de Neurologia do HCFMRP-USP. O chumbo foi medido por espectrometria de absorção atômica com forno de grafite, e o fósforo foi medido colorimetricamente para determinarmos a profundidade da microbiópsia. Uma vez que a profundidade da microbiopsia não pode ser prevista, mas é um factor que influencia o resultado e que temos conhecimento que as concentrações de chumbo diminuem a partir da superfície para o interior do esmalte uma fórmula matemática foi utilizada para calcular a quantidade de chumbo que seria teoricamente encontrada em cada dente à mesma profundidade, e à profundidade seleccionada foi a média de todas as profundidades. As mães ou acompanhantes responderam a um questionário sobre fatores de risco de exposição ao chumbo. Os diagnósticos neurológicos foram obtidos por análise dos prontuários, posteriormente às microbiópsias, sendo criados cinco grupos independentes de crianças, com base na queixa principal: 1 - síndrome motora, SM $(\mathrm{N}=31) ; 2$ - epilepsia, $\mathrm{E}(\mathrm{N}=25) ; 3$ - cefaléia, $\mathrm{C}(\mathrm{N}=13) ; 4$ - dificuldade escolar, $\mathrm{DE}$ $(\mathrm{N}=11) ; 5$ - distúrbio do comportamento, $\mathrm{DC}(\mathrm{N}=32)$.

Resultados: A profundidade média das microbiópsias foi $3,16 \mu \mathrm{m}$. Nas concentrações de chumbo obtidas não houve distribuição de Gauss, assim os valores de média, valores máximos e mínimos obtidos em cada grupo foram: 1 - 103,0, 395,$0 ; 2,0.2$ - 64,8, 233,0; 4,0. 3 -140,3,434,0; 10,0. 4 -135,8, 366,0; 38,0. 3 $158,3,476,0 ; 1,9$. A análise dos valores de chumbo evidenciou que não houve correlação entre a idade das crianças e os valores de chumbo (Pearson $r=-0,016 ; p$ $=0,86$ ). Não se observou diferença significativa entre os gêneros (t-test $p=0,55$ ) e também entre os dentes decíduos e permanentes (t-test $p=0,11$ ). Quanto aos grupos com diagnósticos neurológicos, comparando os cinco grupos (ANOVA oneway), houve significância com valor de $p=0,004$. O pós teste de Tukey evidenciou diferença significativa, sendo menores os valores de chumbo no grupo com epilepsia em relação aos grupos com dificuldade escolar e distúrbio de comportamento. $\mathrm{Na}$ análise dos fatores de risco, ocorreu maior número de crianças que brincam com pilhas no grupo cuja queixa principal era cefaléia em relação ao grupo com deficiência motora $(p=0,002)$. Não houve diferenças significativas, em nível de $5 \%$, 
quanto aos valores de chumbo entre os casos com respostas positivas $(p=0,53)$ ao questionário, nem entre as negativas $(p=0,99)$ e nem entre ambos, comparando-se cada um dos fatores. O mesmo ocorreu na análise intragrupo para cada um dos cinco grupos de diagnósticos e entre os grupos.

Conclusões: No presente estudo, encontramos maiores valores de chumbo no esmalte superficial em grupos de crianças com dificuldade escolar e distúrbio do comportamento em relação àquele com epilepsia; e ainda, o achado de que os fatores ambientais de risco estudados não tiveram relação com as diferenças observadas entre esses grupos suscita indagações e necessidade de aprofundamento em pesquisas sobre os efeitos danosos do chumbo no tecido neural, mesmo quando se trata de uma população que vive em áreas consideradas sem risco ambiental e com valores de chumbo no sangue (quando são medidos, o que não é o caso deste estudo) abaixo do limite de intervenção.

Palavras - chaves: dentes, esmalte dental, chumbo, alterações neurológicas. 


\section{Abstract}

Saiani, RAS. Concentration of lead in teeth of children with neurological disorders [dissertation]. Ribeirão Preto: Faculdade de Odontologia de Ribeirão Preto da Universidade de São Paulo; 2012.

Background: The environmental exposure to lead is a serious issue from the standpoint of public health, because when it occurs in the first months and years of life it can lead to serious neurological and behavioral consequences.

Objectives: 1 - To determine the concentration of lead obtained by an micro biopsy in vivo on permanent teeth enamel or deciduous teeth of patients with neurological problems in outpatient treatment in HCFMRP-USP and compare results in different groups according to diagnosis. 2 - To check the profile of the values of lead according to information related to exposure to the metal of these patients.

Method: A micro biopsy was performed in vivo on enamel of children 5-12 years of both genders, attended sequentially, without knowledge of the disease in two clinics in the area of Neurology, USP-HCFMRP. Lead was measured by graphite-furnace atomic absorption spectrometry, and phosphorus was measured colorimetrically to determine the depth of the micro biopsy. Since the micro biopsy depth cannot be anticipated, but is a factor that does influence the result, since lead concentrations are known to decrease from the surface to the inner enamel, a mathematical formula was used to calculate how much lead would be theoretically found in each tooth at the same depth, and the depth selected was the mean of all depths obtained. The mothers or caretakers answered a questionnaire on risk factors for lead exposure. The neurological diagnoses were obtained by analyzing the charts, then the micro biopsy, and created five independent groups of children based on chief complaint: 1 - motor impairment, MI ( $\mathrm{N}=31), 2$ - epilepsy, $\mathrm{E}(\mathrm{N}=25), 3$ - headache, $\mathrm{H}(\mathrm{N}=$ 13), 4 - school difficulties, SD $(N=11), 5$ - behavioral disorder, $B D(N=32)$.

Results: The mean micro biopsy depth of all tests was $3.16 \mu \mathrm{m}$. The lead concentrations obtained did not follow Gaussian distribution, and median, maximal and minimum values for each group are as follows: $1-103,0,395,0 ; 2,0.2-64,8$, 233,$0 ; 4,0.3-140,3,434,0 ; 10,0.4-135,8,366,0 ; 38,0.3-158,3,476,0 ; 1,9$. The analysis of lead values showed no correlation between the age of the children and the values of lead (Pearson $r=-0.016, p=0.86$ ). There was no significant difference between genders ( $t$-test $p=0.55$ ) and also between the primary and permanent teeth (t-test $p=0.11$ ). As for the groups with neurological disorders, comparing the five groups (one-way ANOVA) showed significant $p$-value $=0.004$. The post Tukey test showed significant differences, with smaller values of lead in the group with epilepsy compared to those with school difficulties and behavior disorders. In the analysis of risk factors, a greater number of children playing with piles in the group whose main complaint was headache in the group with motor disabilities $(p=0.002)$. There were no significant differences in the $5 \%$ level, about the values of lead among the cases with positive responses $(p=0.53)$ to the questionnaire or between the negative $(p=0.99)$ nor between the two, comparing each of the factors. The same is true for the intragroup each of the five diagnostic groups and between groups. 
Conclusions: In the present study, we found higher values of lead in the enamel surface in groups of children with school difficulties and behavioral disturbances in relation to that with epilepsy, and also the finding that environmental risk factors studied were not associated with the differences observed between these groups raises questions and need for further research on the harmful effects of lead on neural tissue, even when the population leaves in an environment with no known contamination with lead and shows blood lead concentrations (which is not the case of this study) that are lower than the values considered harmful to health.

Keywords: teeth, enamel, lead, neurological disorders. 


\section{Sumárío}

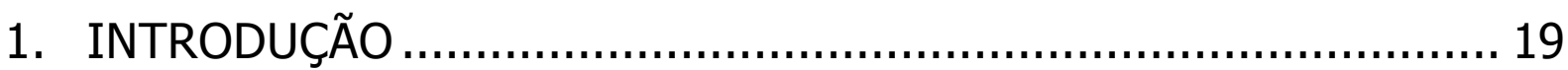

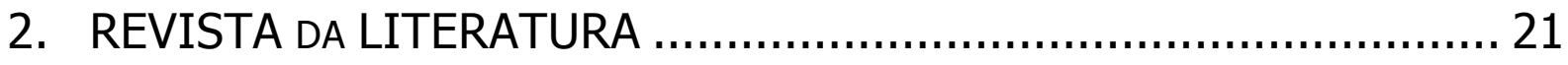

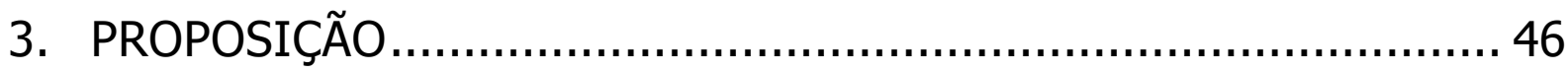

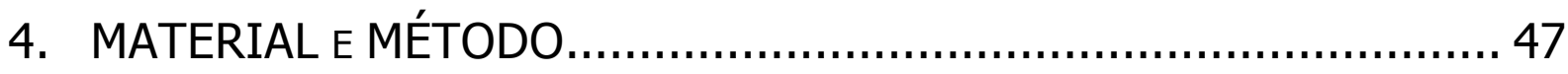

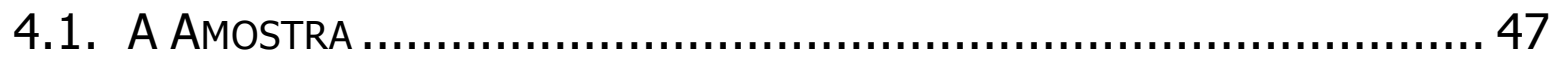

4.2. LoCAL E PROCEDIMENTO DE COLETA dOS DADOS............................. 47

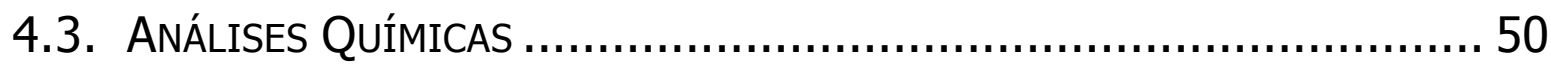

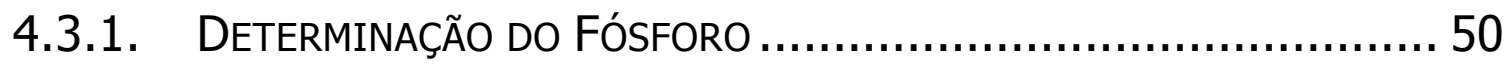

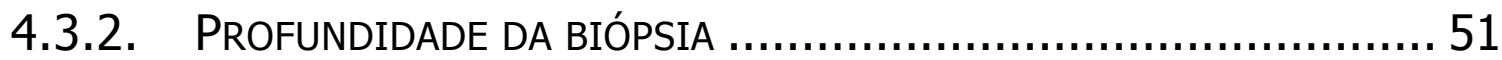

4.3.3. DETERMINAÇÃO DE CHUMBO............................................. 52

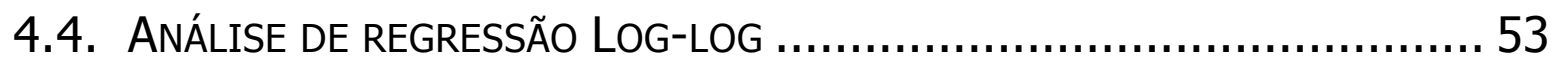

4.5. FORMAÇÃO DOS GRUPOS DE CRIANÇAS DE ACORDO COM O DIAGNÓSTICO

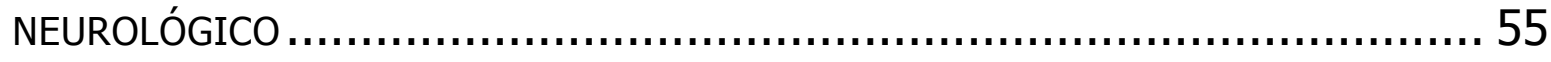

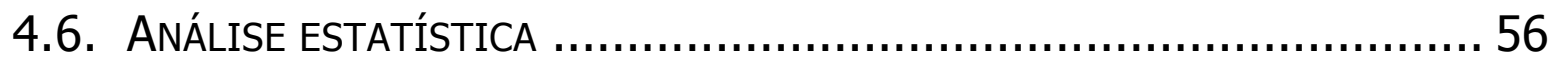

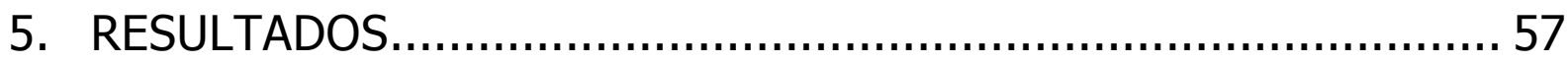

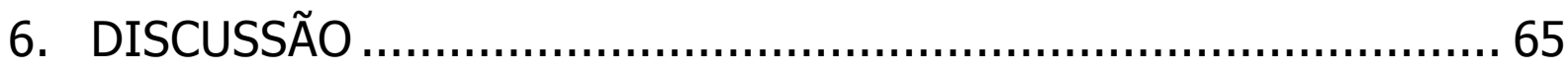

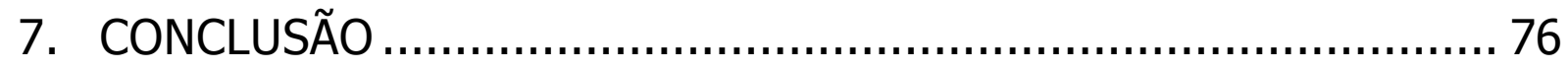

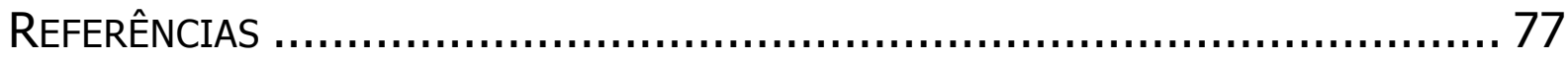

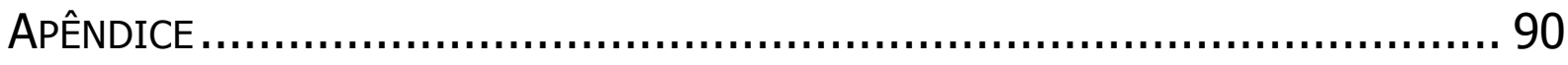

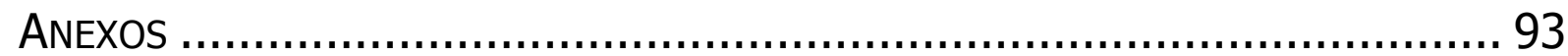




\section{INTRODUÇÃO}

Desde os tempos antigos, o chumbo tem sido conhecido por seus efeitos tóxicos na saúde humana (Major, 1931). Hoje, o chumbo é reconhecido como uma neurotoxina devastadora. Existe uma generalizada contaminação do ambiente por chumbo, e a ampla gama de efeitos tóxicos associados com este metal, e as milhões de pessoas afetadas em todo o mundo, tanto em nações pobres e em desenvolvimento, tornaram este neurotóxica insidiosa e onipresente e um problema de saúde pública com magnitude mundial (Needleman et al., 1979; Satcher, 2000; Olympio et al., 2009).

Ao longo dos últimos anos, houve um aumento no interesse do acúmulo de metais pesados no corpo humano e em seus efeitos danosos, causados por um crescimento da contaminação ambiental (Haavikko et al.,1984). Metais como o zinco e cobre são conhecidos por elementos essenciais, pois participam de funções metabólicas específicas e fazem parte da constituição de várias enzimas; já o chumbo e cádmio são elementos não essenciais e exercem efeitos tóxicos no sistema biológico (Attramadal e Jonsen, 1976).

O chumbo é um metal pesado muito tóxico, mesmo em baixas concentrações. Ainda não foi possível estabelecer uma concentração considerada "segura" para exposições. A toxicidade ao metal é atribuída principalmente a alterações enzimáticas, como a inibição da enzima delta aminolevulínico desidratase (ALAD) e à habilidade de competir com o cálcio. Este metal pode atingir diversos sistemas no organismo. Os efeitos da exposição a doses elevadas são distúrbios gastrointestinais (dores abdominais, constipação e paralisias intestinais) anemia, além do comprometimento do sistema nervoso (Gidlow, 2004; Mudipalli, 2007). Indivíduos 
expostos a concentrações baixas, em torno de $2 \mu \mathrm{g} / \mathrm{dL}$, além dos distúrbios neurológicos, apresentam efeitos como hipertensão (Selevan, 1988; Rothenberg, 2002) e danos ao aparelho cardiovascular e renal (Fleischer et al., 1980; Cooper et al.1985; Selevan, 1985).

O contato com o metal se dá principalmente através das vias respiratória e gastrointestinal. Uma vez absorvido, cerca de $99 \%$ do metal permanece ligado aos eritrócitos por aproximadamente 30-35 dias e num prazo de 4 a 6 semanas estará disperso nos tecidos moles como o fígado, rins, pulmão e sistema nervoso (Rabinowitz, 1991; Patrick, 2006).

A contaminação pelo chumbo já afetou milhões de pessoas, tanto em países desenvolvidos quanto em países subdesenvolvidos e seus efeitos adversos na saúde já são cientificamente comprovados, fazendo com que essa questão tenha se tornado um problema de saúde pública global. A eliminação do chumbo de importantes fontes de contaminação, como tintas contendo chumbo e a gasolina, pode ser considerada um dos maiores triunfos da saúde pública, pois a partir desse período, os níveis de chumbo no sangue, o principal biomarcador utilizado em estudos populacionais, tem evidenciado um considerável declínio (Souza Guerra, 2010). Mas fontes de exposição são rotineiramente encontradas em diversos tipos de indústrias (mineração, pintura, cerâmica, baterias) e infelizmente os desastres decorrentes da exposição ambiental são descobertos apenas anos ou décadas mais tarde. O chumbo é considerado um dos poluentes mais perigosos para a saúde infantil, seu efeito neurotóxico é comum, e, de acordo com a OMS, que afirma que a cada dia morrem no mundo 5500 crianças vítimas de envenenamento por poluentes ambientais. 


\section{REVISTA DA LITERATURA}

\section{O Chumbo e a contaminação ambiental}

$\mathrm{O}$ chumbo (do latim plumbum) é um elemento químico de símbolo $\mathrm{Pb}$, pertencente ao grupo IVA da classificação periódica dos elementos químicos. À temperatura ambiente, o chumbo encontra-se no estado sólido e é um típico metal pesado (Greninger et al., 1978) com um peso atômico relativamente alto.

É um metal encontrado na natureza em estado livre, bem como em composição com vários outros elementos. Apresenta número atômico igual a 82, peso atômico igual a 207,21 u e ponto de fusão igual a $327^{\circ} \mathrm{C}$. A partir de $550^{\circ} \mathrm{C}$ começa a produzir vapor, entrando em ebulição ao atingir cerca de $1740^{\circ} \mathrm{C}$. Em interação com outros elementos dá origem a compostos tais como sulfato de chumbo, cromato de chumbo, arsenato de chumbo, dióxido de chumbo, brometo de chumbo, chumbotetraetila, chumbo-tetrametila, litargírio $(\mathrm{PbO})$, zarcão (Pb304), alvaiade [PbCO3.Pb(OH)2] (Spínola et al., 1980).

Devido ao seu baixo ponto de fusão, ductibilidade e facilidade em formar ligas metálicas, o chumbo foi um dos primeiros metais a serem manipulados pelo homem, que já desde a antiguidade o utilizava na fabricação de utensílios, armas e adornos. Foi, no entanto, a partir do século XVIII que sua utilização atingiu grande escala, quando passou a ser incorporado aos processos industriais então nascentes (Audesirk, 1985).

É um metal tóxico, pesado, macio, maleável, sem gosto, não possui cheiro característico e mau condutor de eletricidade. Apresenta coloração branco-azulada quando recentemente cortado, porém adquire coloração acinzentada quando exposto 
ao ar. Somente em quantidades mínimas é possível encontrá-lo em seu estado natural, ou seja, puro. Os minerais mais comuns são a galena - sulfeto de chumbo, a cerusita - carbonato de chumbo, e a anglesita - sulfato de chumbo (Warren, 2000).

A maioria dos altos níveis de chumbo encontrados por todo o ambiente tem origem nas atividades humanas. Um dos principais usos do chumbo é na produção e reciclagem de alguns tipos de baterias e placas elétricas. Ele também é utilizado na produção de munição, na manufatura da borracha, nas soldas e materiais de revestimento na indústria automotiva, como ingrediente nas tintas, vitrificados, esmaltes e vidros, nos pigmentos e inseticidas. Alguns compostos químicos do chumbo (chumbo tetraetila e tetrametila) eram adicionados à gasolina como substância antidetonante. Seu uso foi limitado nos anos 80 e em 1996 cerca de $80 \%$ de toda gasolina vendida no mundo já estava sem chumbo. Algumas fontes de liberação de chumbo no ar incluem a queima de combustível, processos industriais e a queima do lixo. A fonte de chumbo na poeira e solo inclui as partículas de chumbo que caem do ar ou trazidas pelo vento, e o desgaste e raspagem das tintas que possuem chumbo dos prédios e outras estruturas. Uma vez que o chumbo vai para a atmosfera, ele pode viajar milhares de quilômetros se as partículas forem pequenas. Esse chumbo é removido do ar pela chuva ou queda das partículas no solo ou superfície da água (Goyer e Clarkson, 2001).

\section{Fontes de exposição ao chumbo}

As fontes de exposição ao chumbo não são as mesmas em todos os países. A exposição ao chumbo pode ocorrer por meio de alimentos, água e poeira contaminada, encanamentos revestidos com chumbo, atividades industriais como 
mineração e processamento de chumbo, além de fábricas de reciclagem de baterias, cerâmicas e tintas (Lappalainen e Knuuttila, 1979; Lanphear et al., 1998; Warren, 2000; Ryan et al., 2004; Babosa et al., 2005; Nriagu et al., 2006).

No Brasil a indústria produtora de chumbo produz cerca de $0,003 \%$ da produção mundial, sendo que nos últimos anos, esse quadro tem sofrido um declínio significante. Atualmente, os principais consumidores de chumbo no país são os fabricantes de baterias ( $80 \%)$, seguido por óxidos e pigmentos (12\%) e setores elétricos e eletrônicos (8\%) (Paoliello e De Capitani, 2005).

\section{Toxicocinética do chumbo}

No organismo humano, o chumbo não é metabolizado, e sim, complexado por macromoléculas, sendo diretamente absorvido, distribuído e excretado. Os compostos de chumbo inorgânico entram no organismo por inalação (rota mais importante na exposição ocupacional) ou ingestão (via predominante para a população em geral). Somente os compostos orgânicos de chumbo são capazes de penetrar através da pele íntegra (Tsalev e Zaprianov,1985).

A absorção do chumbo se dá pelas vias aéreas superiores, no caso de poluição do ar, ou por ingestão e absorção através do trato gastrointestinal (Calabrese et al., 1996). Quando ocorre absorção gastrointestinal, a porcentagem de absorção é diferente, em se tratando de adultos e crianças. Enquanto os indivíduos adultos absorvem em torno de 10 a $15 \%$ e armazenam cerca de $5 \%$ do que é absorvido, as crianças absorvem cerca de $41,5 \%$ e retém 38,1\% (Ziegler et al., 1978). Associado a isso, as crianças são mais suscetíveis à intoxicação devido ao hábito de levar as mãos e objetos à boca (Bellinger, 2004). 
O efeito tóxico em crianças é aumentado também, pois o chumbo depositado nos ossos fica em constante mobilidade devido ao seu crescimento. O esqueleto, na primeira infância, aumenta quarenta vezes em relação à sua massa original, e durante esse período há uma maior capacidade de acumular chumbo (Schaffner, 1981).

A fração de chumbo que é absorvida depende principalmente da sua forma física e química, particularmente do tamanho da partícula e a solubilidade do componente específico, além de características como idade, estado fisiológico, fatores genéticos e condições nutricionais do indivíduo (Agency for Toxic Substances and Disease Registry - ATSDR, 1999). Em condições sistêmicas alteradas, como em casos de alterações de ferro, cálcio e zinco, a absorção é aumentada (Wright et al., 1998, 1999, 2003; Bradman et al., 2001), a diminuição da absorção do chumbo por ingestão de cálcio deve-se à competição entre os dois elementos (Fullmer et al., 1985).

A absorção cutânea dos compostos inorgânicos de chumbo é pequena. Ocorre apenas no caso da pele estar lesada. Por outro lado, os compostos orgânicos, por serem lipossolúveis, podem ser absorvidos através da pele intacta (Agency for Toxic Substances and Disease Registry - ATSDR, 1999).

Após sua absorção, o chumbo passa a ser distribuído para outros tecidos, através da corrente sanguínea. No sangue, aproximadamente $99 \%$ é encontrado nos eritrócitos e apenas 1\% permanece no plasma (Schutz et al., 1996). Estudos têm indicado que mais de $80 \%$ do chumbo nos eritrócitos está, principalmente, ligado à enzima ácido $\delta$ - aminolevulínico desidratase (ALAD) (Bergdahl et al.,1999). O metal é então distribuído entre os tecidos moles e mineralizados (Rabinowitz, 1991). O 
restante que permanece no plasma, como íon livre ou ligado à albumina, difunde-se para o sistema nervoso central (O'Flaherty, 1995).

Em estudos cinéticos com isótopos estabilizados de chumbo, Rabinowits et al. (1976) conseguiram desenvolver um modelo clássico envolvendo três compartimentos, que esclarecia a distribuição do chumbo no organismo. No primeiro compartimento, produz-se uma troca rápida entre o sangue, os fluidos biológicos e tecidos moles como fígado, rim e cérebro, que correspondem a $4 \%$ da carga corpórea total, a menos que haja uma exposição aguda, com uma meia-vida de um mês. No segundo compartimento, ocorre um intercâmbio médio entre os tecidos moles e os ossos, o qual tem uma troca ativa de um ano. O terceiro constitui um compartimento lento e é formado pelo tecido ósseo, que corresponde a cerca de 94\% da carga corpórea de chumbo com uma meia vida de cerca de treze anos. Em crianças, o osso representa 70\% da carga corpórea de chumbo (Schroeder e Tipton, 1968; Leggett, 1993), de onde este pode ser mobilizado e contribuir para os níveis do metal no sangue em pessoas anteriormente expostas.

A excreção ocorre principalmente por filtração glomerular renal podendo também em menor grau ser excretado com fluidos corporais, incluindo o leite durante o aleitamento materno (Gulson et al., 1998a). A quantidade de chumbo excretado por via urinária e fecal está diretamente relacionada com a quantidade ingerida (Ziegler et al., 1978).

A Figura 1 apresenta um esquema geral da toxicocinética do chumbo. 


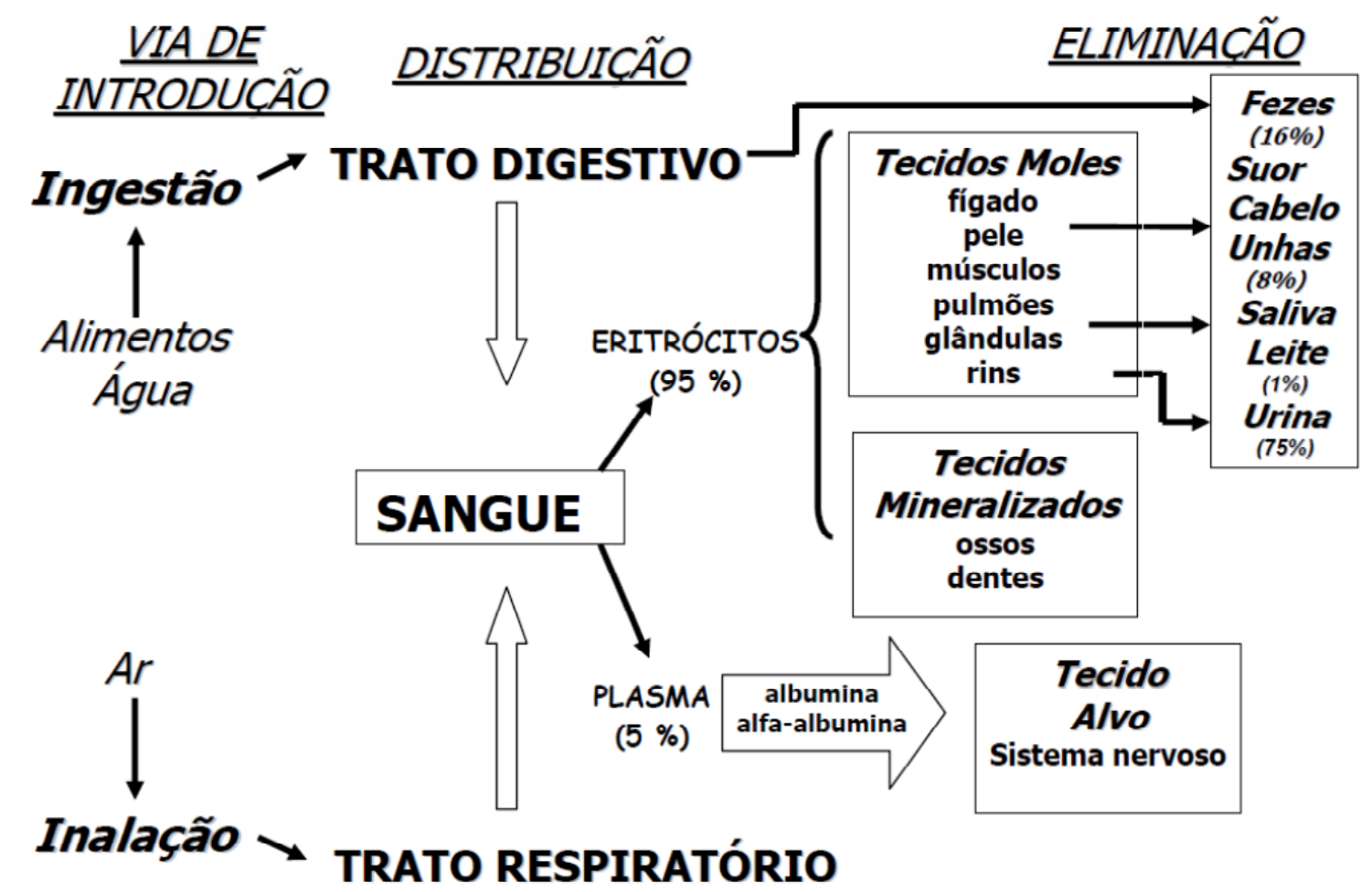

Figura1. Toxicocinética do chumbo Fonte: Tese doutorado Souza Guerra, 2010.

\section{Efeitos tóxicos do chumbo}

O chumbo pode afetar vários sistemas, incluindo o nervoso, hematopoiético, renal, cardiovascular, endócrino e esquelético (Goyer, 1995).

Neste estudo nos ateremos mais nos efeitos neurológicos que serão melhores detalhados abaixo.

\section{Efeitos neurológicos}

Os efeitos danosos do chumbo sobre o sistema nervoso em desenvolvimento vêm recebendo cada vez mais atenção de pesquisadores nas últimas décadas. White e colaboradores (2007) apresentam revisão abrangente dos estudos sobre seus potenciais mecanismos nos processos de aprendizagem e memória, nas relações com o sistema de estresse, liberação de neurotransmissores e plasticidade sináptica, 
configuração da arquitetura neurogênica hipocampal, na diminuição in vitro da GRP78, chaperona envolvida na secreção de IL6 pelos astrócitos, levando à hipótese de que em longo prazo essa deficiência possa estar envolvida na alteração da estrutura proteica relacionada à doenças degenerativas como a de Alzheimer, sugerindo portanto, que a susceptibilidade ao chumbo em período precoce do desenvolvimento poderá causar neurodegeneração na vida adulta.

Os níveis de chumbo no sangue aumentam entre o nascimento e dois anos de idade, com um pico entre 18 e 24 meses, quando as crianças adquirem o hábito de levar objetos à boca. A prevalência em amostra populacional norte americana de níveis acima de $10 \mu \mathrm{g} / \mathrm{dL}$ na idade de um ano foi em torno de $17 \%$ e, retestados aos 24 meses a taxa foi de 29\% (Bernard, 2003). Existem evidências de que em crianças, o chumbo em excesso produz efeitos adversos em rins (Burbure et al., 2006) e sistema hematopoiético (Papanikolaou et al., 2005), interfere no peso ao nascimento (González-Cossío et al., 1997), perímetro craniano (Rothenberg et al., 1999) e há controvérsias quanto ao crescimento (Mahram et al., 2007); reduz a acuidade auditiva e equilíbrio, além de séria interferência nas funções cognitivas (Needleman et al., 1972; Needleman, 1983; Needleman e Gatsonis, 1990). Altos níveis, com registro acima de $100 \mu \mathrm{g} / \mathrm{dL}$ (Coon, 2006) podem causar dores abdominais, vômitos, anorexia, crises convulsivas e até coma (Sathaye e Javadekar, 2000).

Crianças estão expostas a riscos de intoxicação por chumbo desde o período pré-natal. Durante a gravidez e lactação, na mulher ocorre importante mobilização do chumbo da parte óssea para o sangue (Téllez-Rojo et al., 2004), aumentando, portanto o risco para o bebê, tanto na fase pré-natal, não se sabe se embrionária, 
mas com certeza fetal e na de lactente, tendo sido demonstrada correlação entre níveis de chumbo no leite materno e no sangue do recém-nascido (Ettinger et al., 2004). Entretanto não há ainda diretrizes para orientação quanto ao nível de chumbo materno, seja no colostro ou sangue ou ainda ósseo para a suspensão do aleitamento.

Durante a gravidez e a lactação o chumbo depositado no osso pode ser mobilizado (Silbergeld et al., 1988) podendo ocorrer excreção no leite materno (Gulson et al., 1998a). O chumbo atravessa a placenta sendo seus níveis no cordão umbilical correlacionados com a concentração sanguínea de chumbo materna (Amaral et al., 2010). A concentração materna de chumbo no sangue diminui durante a gravidez provavelmente devido à hemodiluíção. A acumulação de chumbo nos tecidos fetais incluindo o cérebro é proporcional à concentração sanguínea materna (Goyer et al., 1995).

O mercúrio e o chumbo são metais tóxicos que afetam principalmente o sistema nervoso central (SNC). A exposição de crianças e recém nascidos a esses metais pode colocar em risco o desenvolvimento e aumentar a vulnerabilidade destes indivíduos. É possível que a exposição a esses metais pesados promova uma degeneração mais acelerada das funções do SNC. O risco da exposição do feto e do lactente ao chumbo depende da absorção deste metal e esta absorção depende da interação do metal com alguns nutrientes, como o fósforo e o cálcio. Este risco também depende do acúmulo do chumbo pelo corpo da mãe com as respectivas interações com o metabolismo do cálcio e fósforo. A exposição materna aos metais é mais importante durante e gravidez que na lactação, porque nesse período, há um consumo maior de cálcio e se não for feita a adequação da quantidade diária a ser 
ingerido, o cálcio será disponibilizado a partir dos ossos, e por similaridade, o chumbo, que apresenta propriedades químicas como o cálcio, será também liberado e passará pela fraca barreira da placenta, elevando assim os riscos de acúmulo no feto (Dórea e Donangelo, 2006).

A toxicidade do chumbo gera desde efeitos claros, ou clínicos, até efeitos sutis, ou bioquímicos. Estes últimos envolvem vários sistemas de órgãos e atividades bioquímicas. Nas crianças, os efeitos críticos atingem o sistema nervoso, enquanto que nos adultos com exposição ocupacional excessiva, ou mesmo acidental, apesar do chumbo causar anormalidades no sistema nervoso central (Muldoon et al., 1996; Schwartz et al., 2000a), os cuidados devem ser com a neuropatia periférica. No entanto, os efeitos no sistema nervoso periférico de adultos tendem a ser reversíveis após a exposição ser cessada (Baker et al., 1985), ao passo que os efeitos centrais nas crianças parecem não ser reversíveis (Needleman et al., 1990; Bellinger et al., 1992; Goldman, 1998), talvez porque o chumbo conduza a perturbações dos processos complexos pelos quais as conexões sinápticas são selecionadas e modificadas (Johnston e Goldstein, 1998).

A intoxicação aguda por chumbo deve ser distinguida da intoxicação crônica. Pacientes com intoxicação aguda apresentam dores de cabeça, hiperexcitação, ataxia, convulsões, coma e até morte. Intoxicações crônicas com níveis não tão elevados de chumbo estão associados a danos neurológicos, como irritabilidade, diminuição de QI, inabilidades de fala, déficits de atenção e distúrbios no desenvolvimento psíquico (Needleman et al., 1979, 1990; Bellinger et al., 1994; Lanphear et al., 2000; Canfield et al., 2003; Bellinger, 2004; Chiodo et al., 2004). Além disso, relatos de sérios transtornos de comportamento em crianças com 
intoxicação por chumbo foram registrados. Comportamentos anti-sociais e de delinquência foram fatores de risco associados mesmo a uma baixa exposição ao chumbo (Needleman et al., 1996; Dietrich et al., 2001).

Com o objetivo de determinar se as concentrações de chumbo pré e pós-natal de crianças no passado estavam associadas com detenções prisionais na juventude, Wright et al. (2008), realizaram medidas das concentrações de chumbo pré-natal durante o primeiro ou início do segundo trimestre de gravidez de mulheres que moravam numa região de casas muito antigas em Cincinnati, Ohio. Os níveis de chumbo no sangue das crianças (nascidas entre 1979 e 1984) foram analisados em uma base trimestral e semestral durante 6 anos e meio. Posteriormente, as informações do total de prisões e detenções por delitos envolvendo violência foram coletadas junto ao Registro de Justiça Criminal de Ohio. Este foi o primeiro estudo prospectivo que demonstrou uma associação entre as concentrações de chumbo pré e pós-natal e comportamento adulto criminoso.

Herbert Needleman foi um dos pioneiros a estudar os efeitos do chumbo na saúde das crianças. Em 1979, realizou um estudo com dentina de dentes decíduos, a fim de documentar os efeitos da exposição ao metal no desenvolvimento intelectual e comportamental destas crianças. Ele relatou que mesmo em concentrações mínimas, particularmente em crianças, o chumbo causa diminuição de QI, inabilidades de fala e atenção e distúrbios no desenvolvimento psíquico (Needleman et al., 1979). Onze anos mais tarde, estes mesmos pesquisadores demonstraram, em um estudo de "follow-up" da mesma população de 1979, que a exposição ao chumbo na infância, mesmo que assintomática, está associada a prejuízos no funcionamento 
do sistema nervoso central que persistem até a adolescência (Needleman et al., 1990).

Em outro estudo de caracterização da longa duração dos efeitos à exposição precoce ao chumbo (Bellinger et al., 1987), crianças foram agrupadas de acordo com a concentração de tal metal no cordão umbilical, e estas foram longitudinalmente seguidas. As crianças do grupo com alto nível de chumbo pré-natal apresentaram menores escores de desenvolvimento cognitivo. Efeitos similares na aprendizagem foram demonstrados em estudos experimentais com primatas, por Gilbert e Rice em 1987. Neste trabalho, macacos rhesus receberam chumbo nos primeiros 100 dias de vida, e apresentaram deficiência na aprendizagem quando adolescentes.

O valor aceitável de chumbo no sangue como limite de neurotoxicidade em crianças decaiu significantemente a partir dos anos 70, assim que estudos populacionais mais sofisticados, com amostras maiores e melhores desenhados e analisados foram conduzidos (Fergusson et al., 1988; McMichael et al., 1988). O consenso sobre qual a concentração de chumbo que é tóxica tem mudado durante os anos. O valor limite abaixo do qual o chumbo não apresenta efeitos adversos não foi identificado (Bellinger, 2004, Binns et al., 2007). Em 1991, o Centro de Controle e Prevenção de Doenças (CDC) dos EUA definiu o nível chumbo no sangue de crianças que deve levar a ações de saúde pública em $10 \mu \mathrm{g} / \mathrm{dL}$. Este valor é interpretado erroneamente como sendo um limite, no qual valores $<10 \mu \mathrm{g} / \mathrm{dL}$ são "seguros" e $\geq$ 10 g/dL são "tóxicos", pois, estudos realizados desde 1991 reforçam evidências de que o desenvolvimento físico e mental das crianças pode ser afetado com concentrações de chumbo no sangue abaixo de $10 \mu \mathrm{g} / \mathrm{dL}$ (Binns et al., 2007). De acordo com Bellinger (2004), nenhum valor único pode ser utilizado como limite, 
separado de um contexto de fatores específicos como idade da exposição e avaliação da concentração de chumbo, duração dos níveis elevados do metal no sangue e características do ambiente no qual a criança vive.

O conjunto de órgãos mais sensível ao envenenamento por chumbo é o sistema nervoso, sendo que a encefalopatia é um dos mais sérios desvios tóxicos induzidos pelo chumbo em crianças e adultos. Além da ausência de um limite preciso, a toxicidade do chumbo na infância pode ter efeitos permanentes, tais como menor quociente de inteligência e deficiência cognitiva. Durante o desenvolvimento de uma criança, o sistema nervoso pode ser afetado adversamente por valores de chumbo no sangue menores do que $10 \mu \mathrm{g} / \mathrm{dL}$, níveis antes considerados seguros (Lanphear et al., 2000; De Genaro, 2002).

A encefalopatia causada pelo chumbo ocorre nas formas aguda e crônica. 0 curso clínico da encefalopatia aguda pelo chumbo varia, dependendo da idade e da condição geral do paciente, da quantidade absorvida, do tempo de exposição e de certos fatores concomitantes. A encefalopatia crônica pode ser um estado residual após a encefalopatia aguda originada por esse metal, mas também pode resultar de uma exposição prolongada ao chumbo (Stewart et al., 2002).

Os sintomas da intoxicação aguda por chumbo incluem: dores de cabeça, irritabilidade, dores abdominais e outros relacionados ao sistema nervoso central. A encefalopatia é caracterizada pela perda do sono e cansaço. As crianças podem ser afetadas por distúrbios de comportamento, dificuldades de aprendizagem e coordenação motora. Em alguns casos, as pessoas podem sofrer de psicoses agudas, confusão mental e redução da consciência, deterioração da memória, redução da habilidade de compreensão das coisas. Alguns indivíduos ainda apresentam uma 
redução da velocidade de transmissão nervosa e também redução da sensibilidade dérmica. Exposições severas geram um sinal característico que é uma linha azul escura na margem gengival. Exposições agudas também podem causar lesões renais, principalmente no túbulo proximal (Järup, 2003).

Carlisle et al. (2009a) relata que a exposição ao chumbo é um problema insidioso, causando efeitos sutis em crianças com níveis baixos de exposição, onde os sinais clínicos não são aparentes e que embora o alvo de concentração de chumbo no sangue (PbS) de dez microgramas por decilitro (10 $\mu \mathrm{g} / \mathrm{dL})$ venha sendo usado como base para tomada de decisões ambientais na Califórnia há quase duas décadas, evidências epidemiológicas recentes sugerem uma relação entre déficits cognitivos e concentrações de chumbo no sangue menores que $10 \mu \mathrm{g} / \mathrm{dL}$.

Em janeiro deste ano o Comitê para Aconselhamento do CDC (Centers for Disease Control's And Prevention) sobre Prevenção de Intoxicação Infantil por Chumbo aprovou uma resolução recomendando a diminuição do limite mínimo de ação para valores de chumbo no sangue de $10 \mu \mathrm{g} / \mathrm{dL}$ para $5 \mu \mathrm{g} / \mathrm{dl}$ (ACCLPP, 2012).

Possivelmente um dos maiores problemas da exposição a "baixas" doses de chumbo (que seriam aquelas às quais estariam expostas as crianças em que os níveis de chumbo no sangue total medidos estão abaixo de $10 \mu \mathrm{g} / \mathrm{dL}$ ) seja realmente não haver forma fidedigna de quantificar a exposição acumulada a este metal, que pode talvez não ser tão baixa. Esse problema decorre da ausência de medidas de chumbo em um tecido em que este se acumula ao longo dos anos. O amplo uso de um marcador cumulativo pode ser benéfico do ponto de vista da identificação individual de crianças expostas a maiores quantidades de chumbo, assim como do 
ponto de vista da possibilidade de realizar estudos mais detalhados sobre os efeitos de chumbo no desenvolvimento intelectual de crianças.

\section{Polimorfismos genéticos}

Polimorfismos genéticos humanos estão sendo altamente correlacionados com algumas doenças, por meio de análises epidemiológicas. Um polimorfismo genético comum no gene humano ALAD (enzima porfobilinogênio sintase - PBGS), tem sido correlacionado com a contaminação ambiental pelo chumbo (Jaffe et al., 2000).

PBGS catalisa os primeiros passos na biossíntese de todos tetrapiroles (heme, vitamina B12, cofator F430, etc). O PBGS humano é uma metaloenzima dependente de Zn (II) única em sua sensibilidade à inibição pelo chumbo. A inibição da PBGS humana é uma das primeiras repostas fisiológicas à intoxicação pelo chumbo (Jaffe et al., 2000). Essa inibição pode causar elevados níveis dessa enzima no plasma e urina e de protoporfirinas eritrocitárias livres. Esse quadro pode resultar em baixas concentrações de hemoglobina no sangue e anemia. Como a anemia leva à diminuição do número de eritrócitos disponíveis para acumular chumbo, a própria anemia pode afetar a quantidade de chumbo no sangue (diminuindo o chumbo no sangue total), ao passo que a quantidade de chumbo no plasma não é afetada (Bergdahl et al., 1999).

As crianças, especialmente nos primeiros anos, exibem certos efeitos tóxicos mesmo quando expostas a baixas concentrações de chumbo, se comparadas a adultos. A anemia decorrente da exposição a chumbo foi relatada em crianças (Schwartz et al., 1990). Bergdahl et al. (1999) demonstraram que há saturação dos sítios de ligação de chumbo nos eritrócitos em crianças expostas a níveis elevados de chumbo, indicando que é possível subestimar a exposição a chumbo quando se 
utilizam apenas resultados obtidos a partir do sangue. Os níveis de chumbo no plasma de crianças e sua relação com anemia e a relação de chumbo no sangue e plasma com variantes genéticos da PBGS ainda não foram esclarecidas.

Em relação ao gene receptor da vitamina $D$, a presença do genótipo $B B$ pode estar associada com uma menor função do receptor, afetando a absorção e distribuição de cálcio pelo organismo. A vitamina $D$ pode influenciar a absorção e distribuição de chumbo, sugerindo que o genótipo BB pode também estar associado com captação de chumbo ou suscetibilidade à sua toxicidade (Montenegro et al., $2006 a, b)$.

\section{Biomarcadores de chumbo}

A avaliação da exposição aos agentes químicos constitui um importante aspecto para a saúde pública, tendo em vista a possibilidade de se prevenir ou minimizar os efeitos da interação dos contaminantes com o organismo humano (Amorim, 2003).

Os estudos dos efeitos das substâncias químicas sobre a saúde possibilitam avaliar o risco da população exposta e constitui o primeiro passo na fixação de normas ambientais para um contaminante químico presente em um meio. $\mathrm{E}$ para isso é importante conhecer a solidez e as limitações dos dados toxicológicos, assim como as informações disponíveis provenientes destes estudos (Amorin, 2003).

Os biomarcadores indicam a exposição individual ao chumbo e sua concentração pode refletir a história de exposição passada ou recente. Inúmeros biomarcadores para chumbo já foram citados na literatura, dentre os quais, sangue, plasma, osso, saliva, cabelo, unha, urina, fezes, dentes, porém cada um deles tem validade variável e revela uma situação específica (Barbosa et al., 2005). 
Bergdahl e Skerfving (2008) apontaram os atributos que precisam ser avaliados em um biomarcador de exposição a chumbo que são: 1) a acurácia e precisão analítica, 2) o custo, 3) as questões práticas de uso (coleta, por exemplo), 4) o que o biomarcador reflete 5) a relação com exposição e 6) a relação com efeitos. Iremos discutir os diferentes biomarcadores à luz destes atributos a seguir.

\section{Utilização do sangue e plasma como biomarcadores para chumbo}

A utilização de biomarcadores de efeito, em alguns casos, pode ser útil. Os biomarcadores de efeito estão correlacionados com os produtos da biossíntese do heme que se formam em maiores quantidades quando as enzimas que participam da via da síntese do heme estão inibidas pelo chumbo. Em casos de exposição a altas doses esses biomarcadores são vantajosos ( $>25 \mathrm{ug} / \mathrm{dL}$ ), principalmente pelo menor custo das medidas e ausência de problemas com contaminação das amostras por chumbo exógeno. Entretanto, quando o chumbo está presente em baixas doses no sangue, esses marcadores deixam de ser úteis, e as medidas diretas de chumbo são mais adequadas (Parsons et al., 1991).

As determinações de chumbo no sangue normalmente são feitas por Espectrometria de Absorção Atômica com Forno de Grafite (GF-AAS), havendo métodos padronizados para sangue (Parsons e Slavin, 1993). O limite de deteç̧ão descrito para esta técnica está em torno de $1 \mu \mathrm{g} / \mathrm{dL}$ e são descritas variações entre medidas da mesma amostra de cerca de $5 \%$, o que é considerado uma variação pequena (Bergdahl e Skerfving, 2008).

Durante as últimas cinco décadas, o sangue total tem sido o principal fluido biológico utilizado para análise da exposição ao chumbo (Rabinowitz, 1995). A 
concentração deste metal no sangue dura em média 30-40 dias, podendo ocorrer um declínio se o indivíduo não for exposto a novas fontes de contaminação (Altshuller et al., 1962; Attramadal e Jonsen, 1976; Brudevold et al., 1977; Needleman et al., 1979; Haavikko et al., 1984; Rabinowitz, 1990, Hu et al., 1998, Ericson, 2001). Isso se deve ao fato do chumbo ser distribuído para os diferentes tecidos do organismo, principalmente os mineralizados, pois o chumbo se comporta de forma muito semelhante ao cálcio (Stewart, 1974). Caso a exposição cesse ou diminua, o mineral depositado nos tecidos ósseos passa a ser liberado na corrente sanguínea. Desta forma, a porcentagem de chumbo proveniente de exposição passada na corrente sanguínea aumenta até que todo o estoque nos tecidos ósseos se esgote (Gwiazda et al., 2005).

Existe uma constante troca de chumbo entre o sangue e o osso, e a concentração de chumbo no sangue corresponde cerca de $5 \%$ do "body burden" total (Rabinowitz, 1993). De um ponto de vista fisiológico, o chumbo no plasma representa o índice mais relevante de exposição, distribuição e risco à saúde, se comparado com o chumbo no sangue total, pois a fração plasmática está em continuidade com o líquido intersticial dos tecidos (Barbosa et al., 2005). Existem vários relatos de chumbo no plasma em que a validação dos dados é fraca ou ausente. Isso porque não há um material de referência certificado para este metal no plasma (Cake et al., 1996).

O CBLI (Cumulative Blood Lead Index) pode ser útil para ter uma medida cumulativa, mesmo que as medidas de sangue não tenham sido obtidas de forma sistemática a intervalos regulares. Esse índice se baseia no uso da área sob a curva de chumbo no sangue traçada para um determinado indivíduo para calcular a 
exposição, assim se tem como parâmetro as concentrações e o tempo (Hu et al., 2007).

A avaliação dos efeitos do chumbo na saúde humana deve levar em conta a variabilidade na suscetibilidade individual a efeitos para uma mesma concentração de chumbo no sangue (Bergdahl e Skerfving, 2008). Isso pode ser resultante de variações individuais em vários polimorfismos genéticos, que parecem caracterizar subgrupos populacionais particularmente suscetíveis aos efeitos do chumbo. Além disso, algumas doenças crônicas como a diabete tipo II têm sido associadas a piores efeitos em concentrações mais baixas de chumbo (Schwartz e Hu, 2007).

Embora agências de saúde e de controle ambiental recomendem limites máximos de exposição ao chumbo, a Secretaria de Segurança e Saúde no Trabalho tem como valor referência de normalidade (VR) o nível sanguíneo de chumbo de 40 $\mu \mathrm{g} / \mathrm{dL}$, e como Índice Biológico Máximo Permitido (IBMP) o nível de $60 \mu \mathrm{g} / \mathrm{dL}$ (Manual de Legislação Atlas: Segurança e Medicina no Trabalho, 1997). Estes níveis estão bem acima daquele estabelecido pela Organização Mundial da Saúde de 20 $\mu \mathrm{g} / \mathrm{dL}$ como limite máximo para a população adulta. No caso das crianças, que são mais susceptíveis aos efeitos do chumbo, este limite é de $10 \mu \mathrm{g} / \mathrm{dL}$ (World Health Organization: Regional Office for Europe: air quality guidelines, 1986).

\section{Utilização do osso como biomarcador para chumbo}

O osso, assim como o sangue, também pode ser utilizado como biomarcador, porém, devido ao processo de remodelação óssea, a concentração encontrada deve ser correlacionada com a intensidade e período de exposição a esse metal (Hu et al., 1998). Outra desvantagem seria a necessidade de procedimentos invasivos para 
obtenção desses dados. Recentemente procedimentos não invasivos, porém de elevado custo, como fluorescência de raios-X (XRF) têm se mostrado promissores quando se trata da determinação da concentração de chumbo no osso (Hu et al., 1998; Todd et al., 2000). A adaptação do uso de XRF para uso in vivo começou em meados de 1980 (Hu et al., 1998), e os primeiros resultados de estudos populacionais utilizando XRF aparecem em meados da década de 1990 (Hu et al., 2007). O tempo de medida requerido para obter sinal adequado é no mínimo 30 minutos, e é fundamental que a área irradiada esteja totalmente imóvel. A quantidade de radiação emitida tem sido comparada àquela de uma tomada de radiografia odontológica convencional, o que é bastante aceitável do ponto de vista de riscos à saúde (Hu et al., 2007). Autores apontam para o cuidado que se deve ter ao expor crianças, uma vez que a dose recebida por uma criança será muito maior do que a de um adulto em função da presença de medula óssea vermelha na tíbia da criança (Nie et al., 2007). O chumbo do sangue é incorporado em tecidos calcificados como ossos e dentes, e pode permanecer por anos (Rabinowitz 1991, O'Flaherty, 1995). De acordo com Rabinowitz (1991), a meia vida do chumbo no osso pode durar de 10 a 30 anos. 0 estoque de chumbo nos tecidos calcificados depende do turnover que acontece no tecido, e esse processo, por sua vez, vai depender do tipo de osso, que pode ser compacto (baixo turnover) ou trabecular (alto turnover) (O'Flaherty, 1995). Rabinowitz et al. (1989) calculou a capacidade de turnover no osso compacto, que é aproximadamente $2 \%$ por ano e no osso esponjoso ou trabecular, que é em torno de $8 \%$. As descrições mais frequentes são de chumbo na patela e na tíbia. A patela é um osso predominantemente trabecular, onde o tempo de residência do chumbo é de poucos anos. A tíbia é um osso predominantemente 
cortical, sendo as medidas feitas na região da diáfise, na qual o tempo de residência do chumbo é de cerca de 30 anos (Barbosa et al., 2005). Diferenças fisiológicas entre crianças e adultos aumentam a susceptibilidade das crianças aos efeitos deletérios: nos adultos $94 \%$ do "body burden" de chumbo é armazenado nos ossos e dentes, sendo que essa proporção é apenas de 70\% em crianças (Barry, 1981). Além disso, o crescimento contínuo de crianças implica constante remodelação óssea, por causa do desenvolvimento esquelético (O 'Flaherty, 1995). Tal fato contribui para um estado em que o chumbo no osso é continuamente liberado no compartimento sanguíneo, um processo descrito como contaminação endógena (Gulson et al., 1996). Esse processo é particularmente significante em se tratando de mulheres grávidas porque a gravidez causa um aumento da remodelação óssea (Rust et al., 1999).

A concentração média encontrada em indivíduos não expostos a chumbo no ambiente de trabalho e de cerca de $20 \mu \mathrm{g} / \mathrm{g}$ de chumbo no osso, enquanto trabalhadores expostos podem apresentar ate $100 \mu \mathrm{g} / \mathrm{g}$ (Bergdahl e Skerfving, 2008). Devido ao processo de remodelação, trabalhadores com esta concentração no osso podem apresentar $16 \mu \mathrm{g} / \mathrm{dL}$ de chumbo no sangue pela mobilização contínua de chumbo do osso (Barbosa et al., 2005). No caso de mulheres com cerca de $50 \mu \mathrm{g} / \mathrm{g}$ de chumbo no osso, poderão apresentar medidas no sangue de $8 \mu \mathrm{g} / \mathrm{dL}$. Em períodos de intenso remodelamento ósseo, mais chumbo é mobilizado do osso (Barbosa et al., 2005).

Ainda hoje podemos afirmar que medidas realizadas no osso não têm a mesma acurácia e precisão analíticas, e não podem ainda ser feitas em laboratórios comerciais ou governamentais se compararmos com as medidas no sangue (Hu et 
al., 2007). Além disso, o tempo de meia hora para medição e a imobilidade necessária para realização do exame dificultam a medida, que tem uma precisão razoável em homens adultos. Em mulheres e crianças a variabilidade das medidas é muito grande e uma boa porcentagem das medidas de pessoas não expostas ocupacionalmente costuma ser negativa. Apesar destes problemas, o uso de medidas de chumbo acumulado no osso, particularmente no osso cortical, e os dados de CBLI foram fundamentais para a demonstração de que maior exposição cumulativa a chumbo está associada a risco aumentado de doenças crônicas em populações adultas (Schwartz e Hu, 2007).

\section{Utilização de dentes como biomarcadores para chumbo}

Como os dentes são relativamente estáveis, ou seja, não sofrem remodelação como os ossos, eles registram a história de exposição ao chumbo desde sua mineralização (Brudevold e Steadman, 1956; Brudevold et al., 1975; 1977; Cleymaet et al., 1991b; Tvinnereim et al., 2000). Assim, os dentes decíduos e permanentes podem ser utilizados como indicadores da exposição crônica a metais pesados durante a infância (Cleymaet et al., 1991b; Rabinowitz et al., 1991; Tvinnereim et al., 2000). A história da deposição de chumbo nos dentes é, principalmente, importante para estudos dos efeitos da contaminação crônica de chumbo na saúde.

As medidas das concentrações de chumbo no dentes nos trazem informações distintas quanto à exposição a chumbo. Além disso, a facilidade de acesso e realização das medições diretas fez com que esse tecido atraísse a atenção por parte de alguns pesquisadores. 
Existe uma variação muito grande, descrita na literatura, entre as concentrações de chumbo no esmalte dentário (Shapiro et al., 1972; Fergusson et al., 1987; Antilla, 1987; Gil et al., 1994; Arora et al., 2006), que vai de 1.7 até 4.900 ppm (Antilla, 1987; Brudevold e Steadman, 1956). Estudos experimentais utilizando animais mostraram evidências de que o chumbo possui uma distribuição espacial heterogênea no dente, com uma maior concentração na superfície do esmalte (Grobler et al., 2000; Arora et al. 2005).

O esmalte dental parece refletir a exposição passada e atual ao chumbo, mesmo que os níveis sanguíneos tenham voltado ao normal (Needleman e Bellinger, 1991). Esse achado se deve ao fato de não ocorrer turnover da apatita no esmalte, como acontece na remodelação do osso, ou seja, uma vez que o chumbo é depositado, ele não é posteriormente removido (Grobler et al., 2000).

Um aspecto valioso e interessante das medidas de chumbo no esmalte é sua capacidade de elucidar a história de exposição ao chumbo. Os dentes são compostos por tecidos distintos, os quais são formados em diferentes períodos e por isso, suas partes podem refletir diferentes estágios da vida do indivíduo. Por exemplo, o esmalte de dentes decíduos e parte do esmalte de dentes permanentes são formados in útero, fato que pode prover informações da exposição pré natal ao chumbo. Essa informação é valiosa para entendimento da relação dose-efeito das anomalias embrionárias, particularmente em se tratando de disfunção neurotóxica (Gulsson, 1996).

O interesse na utilização do esmalte como biomarcador do chumbo é cada vez maior (Ericson, 2001; Uryu et al., 2003; Rinderknecht et al., 2005), particularmente quando consideramos que as amostras de esmalte superficial são facilmente 
coletadas por meio de biópsia de esmalte, técnica introduzida por Brudevold et al., em 1975, que utiliza uma amostra dos minerais do esmalte obtida por meio de ataque ácido para fazer a análise de chumbo. Contudo, detalhes sobre o mecanismo de acúmulo de chumbo na superfície do esmalte ainda não foram completamente elucidados (Costa de Almeida et al, 2007).

Utilizando dentes, particularmente o esmalte dental, demonstrou-se que são encontradas algumas crianças ou grupos de crianças com níveis relativamente altos de chumbo acumulado nos dentes mesmo em regiões sem contaminação por chumbo descrita. Isso aconteceu, por exemplo, quando foram analisados os níveis de chumbo encontrados no esmalte superficial de dois grupos de pré-escolares de Piracicaba, SP, uma população residente em uma região industrial e outro residente numa região não industrial (Gomes et al., 2004). Verificou-se uma diferença estatisticamente significativa quando se compararam os resultados obtidos para as crianças da região industrial com aqueles das crianças da região não industrial. Esses resultados demonstram que também no Brasil as crianças estão expostas a níveis mais altos de chumbo em alguns ambientes, particularmente em regiões industrializadas de cidades. Posteriormente foram realizados testes no esmalte de 247 crianças de sete EMEIs (Escolas Municipais de Educação Infantil) de Ribeirão Preto, SP, e de 26 crianças de uma região, que se demonstrou contaminada por chumbo (Padula et al., 2006) em Bauru, SP, nas imediações da Fábrica de Baterias Ajax. Os resultados desse trabalho indicaram que o esmalte de dentes decíduos de crianças residentes em regiões contaminadas apresentou cerca de quatro vezes mais chumbo do que o esmalte de crianças residentes em cidades sem uma fonte de contaminação conhecida (Costa de Almeida et al., 2007). Além disso, verificou-se 
que mesmo com a amostragem de 20 a 30 crianças por grupo, é possível identificar regiões mais e menos contaminadas em uma cidade, como foi o que verificamos em Ribeirão Preto, SP, onde foi encontrada uma região da cidade com 35\% das crianças com tanto chumbo quanto a mediana da concentração de chumbo descrita para as crianças de Bauru.

Os dados acerca da concentração de chumbo no esmalte de dentes decíduos são escassos, pois poucos trabalhos utilizaram este modelo como amostra (Gomes et al., 2004; Costa de Almeida et al., 2007).

Alguns autores consideram o esmalte dentário promissor para se detectarem contaminações precoces pelo chumbo (Ericson, 2001; Uryu et al., 2003; Rinderknecht et al., 2005), particularmente quando consideramos que as amostras de esmalte superficial são facilmente coletadas por meio de biópsia de esmalte (teste de esmalte). A primeira descrição do teste de esmalte para determinar chumbo foi feita em 1975, por Brudevold e colaboradores para dentes permanentes extraídos. 0 teste de esmalte é um procedimento de ataque ácido, utilizando-se 1,6 N HCl em 70\% de glicerol. Alguns estudos que a utilizaram em dentes permanentes extraídos (Brudevold et al. 1975; Brudevold e Steadman, 1956), sugeriram uma relação entre o chumbo na superfície do esmalte e os níveis de chumbo ambiental. Esta técnica foi posteriormente adaptada para a utilização in vivo para se obter dados de chumbo na superfície do esmalte em dentes permanentes (Cleymaet et al. 1991a, 1991b, 1991c, 1991d, 1991e), e, recentemente, esse procedimento foi adaptado para obter amostras de esmalte de dentes decíduos (Gomes et al., 2004) e com isso, permitir a coleta de dados a respeito da história da exposição ao chumbo por crianças pequenas, com o objetivo do monitoramento de populações. 
Utilizando a metodologia de coleta de amostras de dente para determinação de chumbo, nosso grupo obteve resultados que sugerem que o chumbo está presente também em cidades brasileiras onde uma contaminação "ambiental" não foi relatada. Isso não é surpresa, pois o chumbo está presente em tantas e tão diversas atividades humanas, que é difícil suspeitar o grau de contaminação sem haver medidas. Em nosso trabalho realizado com 444 escolares de 6-8 anos residentes em Ribeirão Preto, SP, em que as concentrações de chumbo foram estudadas nos dentes, sangue, plasma e saliva, verificamos que a media de chumbo no sangue das crianças ribeirão-pretanas analisadas neste estudo foi $2,4 \mathrm{ug} / \mathrm{dL}$, sendo que $10 \%$ das crianças deste estudo apresentaram chumbo no sangue entre 4 e 9,4 ug/dL (Costa de Almeida et al., 2010). Nos estudos sem medidas de chumbo no sangue, obtivemos uma idéia da concentração de chumbo no esmalte superficial, que nos pareceu excessiva em algumas crianças de Ribeirão Preto, porque alguns dos valores de Ribeirão Preto eram semelhantes estatisticamente aos valores encontrados em crianças de uma região notoriamente contaminada, próxima a Fabrica de baterias da Ajax, em Bauru (Costa de Almeida et al., 2007). Em face destes resultados que apontam um grau talvez pequeno de contaminação de algumas crianças em Ribeirão Preto, isso visto em cortes transversais em escolas públicas, pensou-se que talvez a amostragem de crianças atendidas no Departamento de Neurologia da FMRP/USP apresentasse valores de chumbo altos, pelo menos em algumas condições já anteriormente descritas como associadas a chumbo.

Como este é o primeiro estudo deste tipo, pensou-se em ter inicialmente uma idéia das concentrações de chumbo obtidas em diferentes grupos de condições vistas no Departamento de Neurologia da FMRP/USP. 


\section{PROPOSIÇÃO}

Os objetivos deste trabalho foram:

1- Determinar a concentração de chumbo obtida por meio de testes de esmalte realizados in vivo em esmalte de dentes permanentes ou decíduos de pacientes com problemas neurológicos em tratamento ambulatorial no HCFMRP-USP e comparar os resultados em diferentes grupos de acordo com o diagnóstico.

2- Verificar o perfil dos valores de chumbo segundo informações relacionadas à exposição a esse metal dos referidos pacientes. 


\section{MATERIAL E MÉTODO}

Após a aprovação do projeto pelo Comitê de Ética em Pesquisa da Faculdade de Odontologia de Ribeirão Preto da Universidade de São Paulo - Campus de Ribeirão Preto (processo número - 2008.1.324.58.1), segundo a Resolução 196/96 de 10 de novembro de 1996 da Comissão Nacional de Ética em Pesquisa (CONEP), iniciou-se a seleção das amostras (Anexo A).

\subsection{A AMOstra}

A amostra consistiu de 112 crianças de 5 a 12 anos, de ambos os gêneros, atendidas em dois ambulatórios da área de Neurologia do HCFMRP-USP: Neurologia Infantil Geral, sob a coordenação da Profa. Dra. Carolina A. R. Funayama e no de Epilepsia Infantil, sob a coordenação da Profa. Dra. Regina Maria França Fernandes. Esses pacientes foram selecionados com base na análise dos prontuários de atendimento, buscando-se apenas o critério idade atuais (5 a 12 anos). 0 ambulatório de epilepsia foi incluído por possibilitar um número maior desses pacientes na amostra.

Após concordância e autorização dos responsáveis em participar da pesquisa, estes assinaram um termo de consentimento livre e esclarecido para participação e responderam a um questionário (Anexo $B$ e Apêndice $A$ ).

\subsection{Local e Procedimento de coleta dos dados}

A abordagem ao responsável pelo paciente, a concordância em participar, a aplicação do questionário e a coleta da amostra do esmalte dentário foram realizadas no mesmo dia, no horário dos ambulatórios, no período da tarde, antes ou após o 
atendimento médico, em uma sala que foi destinada para esse fim, junto ao Setor de Enfermagem do HCFMRP-USP.

Posteriormente, em outro momento, fora do período do ambulatório, o prontuário de cada criança foi solicitado ao Serviço de Arquivo Médico do HCFMRP para se coletarem informações sobre a doença neurológica, tarefa esta realizada pela Profa. Dra. Carolina A. R. Funayama, docente responsável pelo Serviço de Neurologia Infantil do HCFMRP-USP. Assim, foram apurados dados sobre a queixa principal da criança e o diagnóstico das doenças.

O procedimento para determinação de chumbo foi realizado sem que os pesquisadores conhecessem o tipo de queixa neurológica da criança no ambulatório geral, nem os detalhes da doença, como tipo e diagnóstico causal no ambulatório de epilepsia.

Para a determinação de chumbo nos dentes foram realizadas microbiópsias no esmalte in vivo em dentes decíduos e permanentes, utilizando-se o método proposto por Brudevold et al., 1975, modificado por Gomes et al., 2004.

Antes de iniciar os procedimentos da microbiópsia, todo o material que seria utilizado e a bancada sobre a qual o instrumental e pipetas seriam dispostos foram limpos com uma solução de ácido nítrico ( $\mathrm{HNO}_{3}$ ) a 10\%, a fim de remover possíveis contaminações prévias pelo chumbo. Os tubos para centrífuga, de poliestireno, tipo eppendorf, e as ponteiras foram, também, previamente deixados em solução de ácido nítrico a 10\% durante 24 horas. Em seguida, esse material recebeu 3 banhos com água deionizada, 2 banhos com água ultrapura (MILI Q) e foram secos em capela de fluxo laminar classe 100 . Todo esse procedimento foi realizado dentro de 
uma sala branca classe 10000. Essa limpeza tinha o objetivo de descontaminação do material para o chumbo.

Os dentes foram submetidos à profilaxia profissional com escova de dente (Figura 2A), em seguida foram lavados com água MILI Q e secos com gaze (Figura 2B). Feito isso, foi feito isolamento relativo com roletes de algodão. Estes procedimentos foram realizados pela auxiliar para que a pesquisadora não tocasse em nenhuma superfície metálica antes da realização da biópsia.

Em seguida, uma fita adesiva (fita mágica, 810 Scotch ${ }^{\circledR}$ - 3M) com uma perfuração de diâmetro 2,01 mm (Figura 2C) foi firmemente aderida à porção central da superfície vestibular do dente, demarcando o local da microbiópsia (Figura 2D). Nesta demarcação foram depositados, com uma micropipeta automática, $5 \mu \mathrm{l}$ da solução de $\mathrm{HCl}$ a $1,6 \mathrm{~N}$ em glicerol a $70 \%(\mathrm{v} / \mathrm{v})$, e agitado suavemente com a ponta do pipetador durante 20 segundos (Figura 2E). A solução da microbiópsia foi aspirada e transferida a um tubo de coleta (tubo tipo eppendorf) contendo $200 \mu \mathrm{l}$ de água ultrapura (MILI Q) (Figura 2E), sendo aplicados em seguida, por 10 segundos, $5 \mu$ de solução de glicerol a $70 \%$ na demarcação, os quais também eram aspirados e adicionados à solução de microbiópsia presente no tubo de coleta.

Finalizando este procedimento, a fita adesiva era removida, o dente era lavado com água, seco e isolado novamente para receber aplicação de flúor neutro em gel.

O controle das microbiópsias de esmalte foi obtido por meio de brancos e por microbiópsias controle na superfície da bancada ou sobre as tampas dos raques para ponteira, a fim de verificar a contaminação pelo chumbo no ambiente de trabalho durante os procedimentos. 

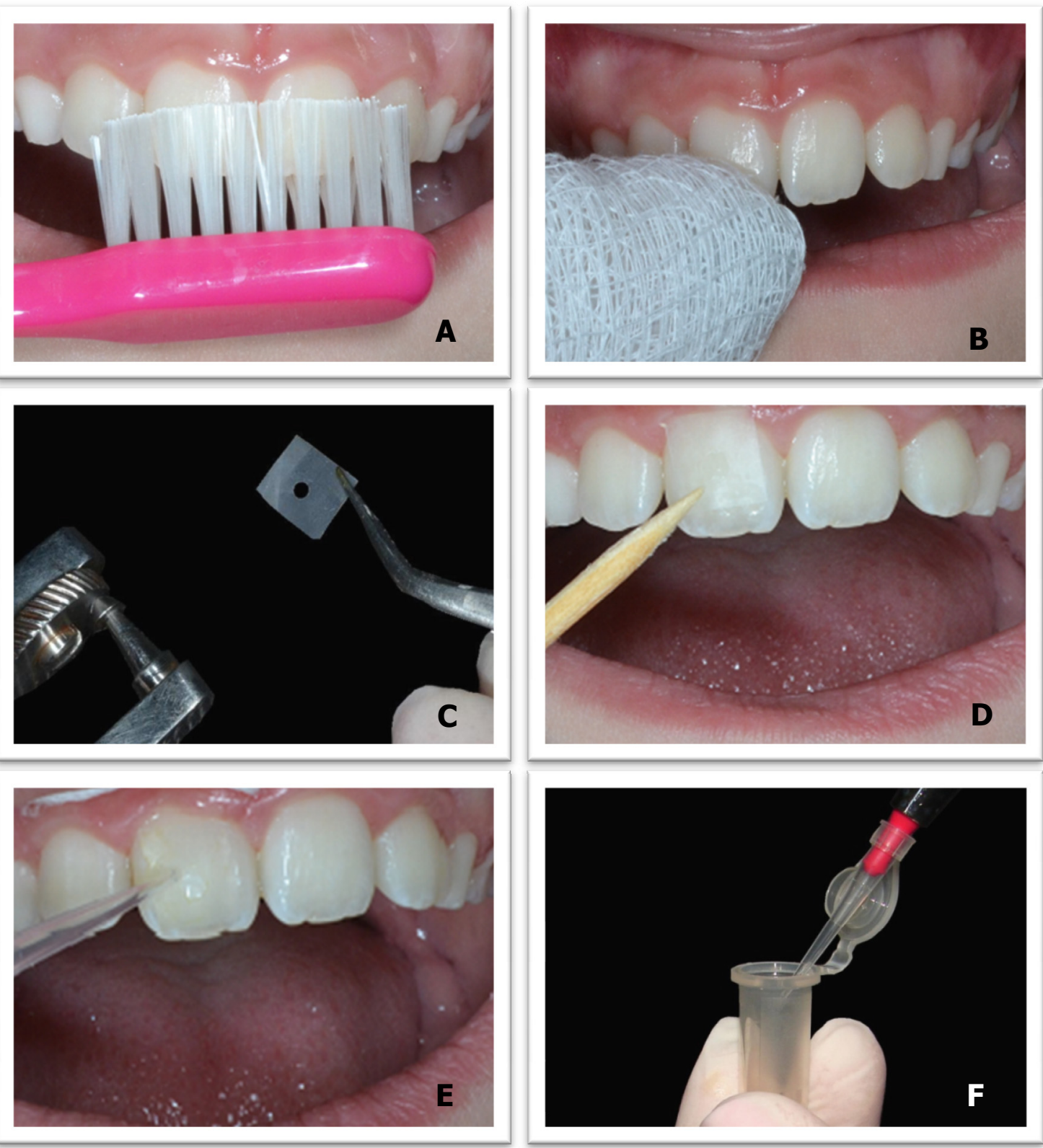

Figura 2. A - Profilaxia do dentes; B - Secagem com gaze; C - Fita com perfuração; D - Colocação da fita; E - Depósito da solução no dente; F - Solução transferida para tubo de coleta.

\subsection{AnÁlises Químicas}

\subsubsection{Determinação do Fósforo}

A fim de determinar a espessura da camada de esmalte removida durante a biópsia, foi dosada a concentração de fósforo inorgânico (P) no esmalte em solução.

As concentrações de fósforo presentes nas amostras foram determinadas pelo método colorimétrico de Fiske e Subbarow (1925), cujo princípio é que o fósforo dos 
fosfatos minerais é transformado em fosfomolibdato, o qual é em seguida reduzido pelo ácido alfa-amino-naftol sulfônico a um produto de cor azul, cuja intensidade de coloração é proporcional ao teor de fósforo inorgânico presente na amostra. A determinação das concentrações de fósforo foi realizada em triplicata. Sendo assim, foram pipetados $30 \mu \mathrm{l}$ de amostra e acrescentou-se $220 \mu \mathrm{l}$ de água deionizada, $50 \mu \mathrm{l}$ de ácido molibdico, agitou-se e após 10 minutos adicionou-se $20 \mu l$ de reativo redutor, agitou-se novamente e, após 20 minutos, a intensidade de cor foi medida em um leitor de Elisa com um comprimento de onda de $660 \mathrm{~nm}$. O aparelho foi calibrado com amostras que apresentavam concentrações conhecidas de fósforo, que foram de: $0 \mu \mathrm{g} / \mathrm{ml}, 1 \mu \mathrm{g} / \mathrm{ml}, 2 \mu \mathrm{g} / \mathrm{ml}, 4 \mu \mathrm{g} / \mathrm{ml}$ e $8 \mu \mathrm{g} / \mathrm{ml}$, utilizadas para a realização da curva de calibração.

\subsubsection{Profundidade da BIÓPSIA}

A concentração de fósforo foi utilizada para o cálculo da quantidade (g) de esmalte removido. Com base em estudos prévios sabe-se que o esmalte humano é formado de cristais de hidroxiapatita (Ca10 (PO4)6(OH)2 ). A hidroxiapatita, principal constituinte do esmalte, contém $17,4 \%$ de $\mathrm{P}$ (Lazzari, 1976) e $37,1 \%$ de Ca (Brudevold et al., 1956), em peso e o esmalte possui uma densidade de 2,95 g/mL (Weidmann et al., 1967). A partir disso foi feito o cálculo da quantidade de esmalte removido e da profundidade da camada da biópsia.

A profundidade foi então calculada usando-se a fórmula do volume do cilindro figura geométrica que se assemelha à camada do esmalte removido. A profundidade equivale, nesta figura, à altura do cilindro, e foi deduzida pela expressão abaixo: $\mathrm{v}=\mathrm{B} \cdot \mathrm{h}(1)$ 
$h=v / B\left(1^{\prime}\right)$

$\mathrm{d}=\mathrm{m} / \mathrm{v}(2)$

$v=m / d\left(2^{\prime}\right)$

Substituindo-se 2' em 1', tem-se:

$h=m / B \cdot d(3)$

$B=n \cdot r^{2}(4)$

Substituindo-se 4 em 3 encontra-se:

$h=m / n \cdot r^{2} \cdot d$

Sendo:

$v=$ volume do cilindro

$B=$ área da base do cilindro

$\mathrm{h}=$ altura do cilindro (profundidade da biópsia)

$\mathrm{d}=$ densidade do esmalte $(2,95 \mathrm{~g} / \mathrm{mL})$

$\mathrm{m}=$ massa do esmalte

$r=$ raio da biópsia

$\Pi=3,14$

Os resultados da profundidade das biópsias foram expressos em $\mu \mathrm{m}$.

\subsubsection{Determinação de Chumbo}

As análises de chumbo foram realizadas por espectrometria de absorção atômica com forno de grafite pela Profa. Dra. Márcia Andréa Mesquita Silva da Veiga do departamento de Química da Faculdade de Filosofia, Ciências e Letras de Ribeirão Preto. Foi utilizado o espectrômetro de absorção atômica AAnalyst 800 (PerkinElmer, Norwalk, EUA), com amostrador automático AS-800 (PerkinElmer) para introdução 
das soluções, e um atomizador em tubo de grafite pirolítico aquecido transversalmente, com corretor de fundo por efeito Zeeman longitudinal. Uma lâmpada de cátodo oco Lumina Lamp (PerkinElmer) para chumbo foi utilizada como fonte de radiação para a determinação deste elemento, operada com corrente de 10 mA. A linha analítica utilizada para todas as determinações de chumbo foi em 283,3 $\mathrm{nm}$, com largura (fenda) de banda espectral $0,7 \mathrm{~nm}$. Os tubos de grafite possuem plataformas integradas com recobrimento pirolítico (PerkinElmer Part No. B3 000641). Como gás inerte de proteção e purga, argônio com pureza de 99,999\% (White Martins, São Paulo, Brasil) foi utilizado.

\subsection{AnÁlise de regressão Log-Log}

Para compararmos a concentração de chumbo em amostras de esmalte superficial foi necessário definir uma equação que nos permitisse calcular a concentração de chumbo em uma mesma profundidade. Nesta equação o ponto x representa a profundidade em $\mu \mathrm{m}$ o y representa a concentração de chumbo em $\mu \mathrm{g} / \mathrm{g}$. Os dados abaixo serão utilizados para exemplificarmos os cálculos realizados.

\begin{tabular}{cc}
\hline $\mathbf{x}$ (Profundidade em $\boldsymbol{\mu m})$ & $\mathbf{y}(\mathbf{P b} \mathbf{~ e m} \boldsymbol{\mu g} / \mathbf{g})$ \\
\hline 1,55 & 633,6 \\
4,05 & 355,19 \\
7,83 & 216,23 \\
10,41 & 124,9 \\
14,16 & 14,59 \\
\hline
\end{tabular}


Computamos os dados e transformamos os mesmos em log natural. Feito isso, realizamos a regressão linear. A regressão linear nos dá o valor de Ln (logaritmo natural) de a (intercept no eixo y, quando $x=0,0$ ) e o $\beta$ (slope).

A equação é dada por:

$$
\begin{gathered}
\operatorname{Ln}(y)=\operatorname{Ln}(a)+\beta \operatorname{Ln}(x) \\
\text { Onde, } y=a x^{\beta}
\end{gathered}
$$

A regressão linear nos dá o valor de In (a). Para deduzirmos o valor de a, calculamos eln $(a)=a$. (Lê-se exponencial do logaritmo natural de a é igual ao próprio a).

Ao realizarmos a regressão linear no Graph Prism 5 determinamos os valores de $\beta$ e $\operatorname{Ln}(a)$

$$
\begin{gathered}
\beta=-1,3855 \\
\operatorname{Ln}(a)=7,5045
\end{gathered}
$$

Calculamos e $\ln { }^{(a)}=a$, onde e $\ln { }^{(7,5045)}=1816,1969$ $y=a x^{\beta}$, substituindo a por 1816, 1969 e $\beta=-1,3855$, temos $Y=1816,1969 . x-$ 1,3855

Por exemplo, se quisermos saber qual a concentração de chumbo numa profundidade de $6 \mu \mathrm{m}$, substituímos 6 em x, ou seja:

$$
y=1816,1969.6^{-1,3855}=1816,1969.0,08353557=151,71704
$$

Neste caso, pode-se dizer que numa profundidade de $6 \mu \mathrm{m}$, a concentração de chumbo encontrada é de $151,71704 \mu \mathrm{g} / \mathrm{g}$ de chumbo.

Esta fórmula matemática permite fazer o cálculo para ter a concentração de chumbo em uma mesma profundidade em todos os dentes analisados. Este cálculo é muito importante, uma vez que a concentração de chumbo diminui na parte mais 
interna do esmalte, de modo que microbiópsias mais rasas tem mais chumbo (Souza Guerra, 2010).

A fórmula foi descrita por Souza Guerra, 2010, porém foi desenvolvida pelo Prof. Dr. Rafael Andrés Rosales Mitrowsky do Departamento de Computação e Matemática, da Faculdade de Filosofia, Ciências e Letras de Ribeirão Preto, USP. Inicialmente os dados de concentração de chumbo na superfície do esmalte de diferentes cidades (Ribeirão Preto, SP; Santo Amaro, BA; Cubatão, SP) e os dados de profundidade de biópsia sofreram transformação logarítmica para sua utilização na regressão linear. A equação é mostrada abaixo, sendo que $x$ representa a profundidade $(\mu \mathrm{m})$ e y é a concentração de chumbo $(\mu \mathrm{g} / \mathrm{g})$.

$$
\begin{gathered}
\operatorname{Ln}(y)=\operatorname{Ln}(a)+\beta \operatorname{Ln}(x) \\
\text { Onde } y=a x \beta
\end{gathered}
$$

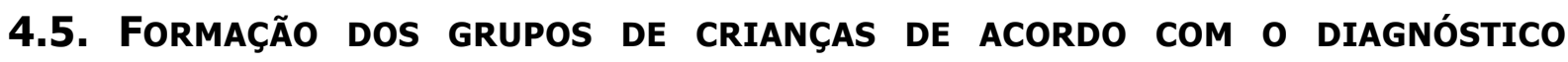 NEUROLÓGICO}

Após a microbiópsia e enquanto se procediam as dosagens do chumbo, os prontuários de atendimento médico das crianças eram revisados no Serviço de Arquivo Médico do HCFMRP-USP por profissional da área (Profa. Dra. Carolina A. R. Funayama), sem que a mesma conhecesse os resultados dos valores de chumbo. Foram criados cinco grupos independentes, com base na queixa principal: 1 síndrome motora $(\mathrm{N}=31) ; 2$ - epilepsia $(\mathrm{N}=25) ; 3$ - cefaléia $(\mathrm{N}=13) ; 4$ - dificuldade escolar ( $\mathrm{N}=11) ; 5$ - distúrbio de comportamento $(\mathrm{N}=32)$.

No grupo com síndrome motora foram incluídos os pacientes com sequelas de lesões cerebrais definidas (paralisia cerebral - 26 casos e distúrbios do movimento, com manifestações extrapiramidais por doenças infecciosas ou degenerativas - cinco 
casos). No grupo com epilepsia, a maioria (16 de 25) era decorrente de lesões cerebrais, principalmente malformações corticais, cinco apresentavam epilepsia centrotemporal com pontas rolândicas, dois com pontas occcipitais do tipo Gastaut e dois com epilepsia generalizada do tipo ausência simples.

No grupo com cefaléia, cinco receberam o diagnóstico de migrânea; e os outros oito restantes, cefaléia tensional.

No grupo com dificuldade escolar, dois apresentavam dislexia (distúrbio específico de leitura e escrita) e, nos demais, nove, a queixa era de dificuldade em todas as matérias escolares.

No grupo com distúrbios do comportamento, sete receberam o diagnóstico de transtorno do déficit de atenção e hiperatividade, e, os 25 restantes apresentavam transtornos de conduta, irritabilidade com agitação ou agressividade, duas das quais tinha autismo definido.

\subsection{ANálise estatística}

Inicialmente todas as variáveis foram analisadas, com 0 intuito de selecionarmos o teste estatístico mais adequado. Como a distribuição dos valores não seguiu a curva de normalidade, os valores foram transformados para Log de base 10 . O nível de significância utilizado em cada uma das estatísticas foi de 0,05 e a análise estatística foi realizada com o Programa Graph Pad Prism (Versão 5.0). 


\section{RESULTADOS}

A concentração de chumbo no esmalte superficial de dentes permanentes e decíduos foi analisada em 112 crianças. Os valores de chumbo nas suas respectivas profundidades obtidos das amostras estão na Tabela 1.

Tabela 1. Dados obtidos das análises de chumbo e fósforo das amostras sendo A (Amostra), Pb (Chumbo), $\mu \mathrm{m}$ (Profundidade).

\begin{tabular}{|c|c|c|c|c|c|c|c|c|}
\hline $\mathbf{A}$ & $\mathbf{P b}$ & $\mu \mathrm{m}$ & A & $\mathbf{P b}$ & $\mu \mathrm{m}$ & A & $\mathbf{P b}$ & $\mu \mathrm{m}$ \\
\hline 1 & 287,04 & 2,9 & 39 & 106,74 & 6,3 & 76 & 138,98 & 2,0 \\
\hline 2 & 24,23 & 1,3 & 40 & 122,79 & 4,0 & 77 & 54,16 & 2,5 \\
\hline 3 & 32,12 & 6,6 & 41 & 67,02 & 5,1 & 78 & 140,15 & 2,3 \\
\hline 4 & 8,55 & 1,9 & 42 & 60,18 & 4,9 & 79 & 253,44 & 2,4 \\
\hline 5 & 390,18 & 3,2 & 43 & 317,53 & 4,5 & 80 & 33,41 & 7,9 \\
\hline 6 & 160,92 & 2,1 & 44 & 119,58 & 5,4 & 81 & 17,18 & 9,9 \\
\hline 7 & 148,15 & 7,2 & 45 & 62,29 & 3,8 & 82 & 69,56 & 1,7 \\
\hline 8 & 425,07 & 1,1 & 46 & 16,72 & 2,4 & 83 & 5,83 & 2,8 \\
\hline 9 & 13,46 & 2,6 & 47 & 69,22 & 5,1 & 84 & 674,59 & 1,2 \\
\hline 10 & 244,72 & 2,4 & 48 & 101,83 & 7,8 & 85 & 22,23 & 0,8 \\
\hline 11 & 60,99 & 2,0 & 49 & 93,85 & 4,4 & 86 & 3,81 & 3,9 \\
\hline 12 & 108,16 & 1,5 & 50 & 178,63 & 7,0 & 87 & 1,79 & 1,7 \\
\hline 13 & 75,11 & 2,2 & 51 & 143,43 & 3,0 & 88 & 3,75 & 3,3 \\
\hline 14 & 65,28 & 5,6 & 52 & 80,63 & 5,0 & 89 & 46,23 & 2,6 \\
\hline 15 & 179,34 & 1,4 & 53 & 22,20 & 6,6 & 90 & 5,83 & 3,9 \\
\hline 16 & 121,16 & 2,2 & 54 & 127,84 & 4,8 & 91 & 205,89 & 1,6 \\
\hline 17 & 170,25 & 2,2 & 55 & 135,53 & 2,5 & 92 & 82,44 & 5,5 \\
\hline 18 & 92,77 & 3,7 & 56 & 228,12 & 3,8 & 93 & 236,26 & 1,5 \\
\hline 19 & 543,72 & 0,9 & 57 & 7,31 & 3,0 & 94 & 10,35 & 2,2 \\
\hline 20 & 2,10 & 2,5 & 58 & 174,48 & 7,8 & 95 & 44,86 & 3,7 \\
\hline 21 & 55,98 & 3,7 & 59 & 68,35 & 8,4 & 96 & 91,92 & 4,4 \\
\hline 22 & 258,41 & 4,3 & 60 & 82,56 & 7,5 & 97 & 38,30 & 3,1 \\
\hline 23 & 111,96 & 3,8 & 61 & 368,91 & 3,2 & 98 & 177,77 & 1,7 \\
\hline 24 & 92,40 & 2,1 & 62 & 87,00 & 3,5 & 99 & 56,60 & 3,0 \\
\hline 25 & 55,30 & 2,2 & 63 & 189,50 & 5,4 & 100 & 38,63 & 1,4 \\
\hline 26 & 286,42 & 2,5 & 64 & 14,80 & 6,5 & 101 & 12,74 & 6,8 \\
\hline 27 & 35,81 & 2,7 & 65 & 124,70 & 7,0 & 102 & 8,90 & 3,8 \\
\hline 28 & 219,06 & 2,4 & 66 & 43,33 & 5,5 & 103 & 40,27 & 5,2 \\
\hline 29 & 93,71 & 1,8 & 67 & 32,54 & 7,5 & 104 & 374,19 & 1,8 \\
\hline 30 & 23,24 & 2,4 & 68 & 21,11 & 5,0 & 105 & 30,79 & 2,7 \\
\hline 31 & 117,72 & 3,2 & 69 & 15,80 & 9,2 & 106 & 3,46 & 6,0 \\
\hline 32 & 364,84 & 2,3 & 70 & 17,41 & 6,6 & 107 & 130,57 & 3,0 \\
\hline 33 & 97,24 & 1,7 & 71 & 218,81 & 1,4 & 108 & 11,84 & 5,8 \\
\hline 34 & 80,20 & 2,1 & 72 & 479,61 & 1,6 & 109 & 32,95 & 9,8 \\
\hline 35 & 181,25 & 3,7 & 73 & 149,60 & 2,3 & 110 & 27,31 & 5,4 \\
\hline 36 & 137,48 & 4,2 & 74 & 221,70 & 2,3 & 111 & 10,83 & 4,2 \\
\hline 37 & 13,00 & 2,6 & 75 & 289,78 & 2,4 & 112 & 32,38 & 2,3 \\
\hline 38 & 82,17 & 2,7 & & & & & & \\
\hline
\end{tabular}


Uma vez que a profundidade da microbiopsia não pode ser prevista, mas é um fator que influencia o resultado e que temos conhecimento que as concentrações de chumbo diminuem a partir da superfície para o interior do esmalte uma fórmula matemática foi utilizada para calcular a quantidade de chumbo que seria teoricamente encontrada em cada dente à mesma profundidade, e a profundidade seleccionada foi a média de todas.

Com os dados da concentração de chumbo no esmalte superficial dos dentes decíduos e permanentes das amostras e os dados da profundidade de microbiópsias citados na Tabela 1 fizemos então as análises de regressão linear loglog. A partir dessas análises e utilizando-se a equação da reta estabelecida no trabalho de Souza Guerra (2010) e mencionada na metodologia, pudemos calcular a concentração de chumbo em uma mesma profundidade em cada uma das amostras.

Após os cálculos obtivemos todos os valores da concentração de chumbo em uma mesma profundidade ou profundidade média de 3,16 $\mu \mathrm{m}$.

Estes foram então analisados quanto à normalidade e concentração de chumbo no esmalte superficial nos cinco grupos formados e relatados na metodologia. Os valores seguem na Tabela 2.

Tabela 2. Concentração de chumbo entre os cinco grupos de diagnósticos analisados.

\begin{tabular}{lccccc}
\hline & $\begin{array}{c}\text { Síndrome } \\
\text { motora }\end{array}$ & Epilepsia & Cefaléia & $\begin{array}{c}\text { Dificuldade } \\
\text { escolar }\end{array}$ & $\begin{array}{c}\text { Distúrbio do } \\
\text { comportamento }\end{array}$ \\
\hline $\mathbf{N}$ & $\mathbf{3 1}$ & $\mathbf{2 5}$ & $\mathbf{1 3}$ & $\mathbf{1 1}$ & $\mathbf{3 2}$ \\
Mínimo & 2,0 & 4,0 & 10,0 & 38,0 & 1,9 \\
Q1 & 23,0 & 7,0 & 50,0 & 113,0 & 54,8 \\
Mediana & 76,0 & 37,0 & 60,0 & 122,0 & 116,0 \\
Q3 & 160,0 & 101,0 & 258,5 & 134,0 & 228,8 \\
Maximo & 395,0 & 233,0 & 434,0 & 366,0 & 476,0 \\
Media & 103,0 & 64,8 & 140,3 & 135,8 & 158,3 \\
Desvio Padrão & 96,3 & 66,9 & 138,6 & 81,3 & 129,6 \\
Erro Padrão & 17,3 & 13,3 & 38,5 & 24,5 & 22,9 \\
\hline
\end{tabular}


Como esses valores não seguiram a curva de normalidade, foram transformados para logaritmo de base 10 (Tabela 3).

Tabela 3. Amostra (A), gênero (G), chumbo (PB) na profundidade de 3,16 $\mu \mathrm{m}$, logaritmo do chumbo de base 10 (Pb Log10) na profundidade de 3,16 $\mu \mathrm{m}$.

\begin{tabular}{|c|c|c|c|c|c|c|c|c|c|c|c|}
\hline A & G & $\mathbf{P b}$ & Pb $\log 10$ & A & G & $\mathbf{P b}$ & Pb $\log 10$ & A & G & $\mathbf{P b}$ & $\mathrm{Pb} \log 10$ \\
\hline 1 & $M$ & 261 & 2,42 & 39 & $\bar{M}$ & 227 & 2,36 & 76 & $\bar{F}$ & 82 & 1,91 \\
\hline 2 & $M$ & 9 & 0,95 & 40 & $M$ & 160 & 2,20 & 77 & $M$ & 42 & 1,62 \\
\hline 3 & $M$ & 73 & 1,86 & 41 & $M$ & 113 & 2,05 & 78 & $M$ & 98 & 1,99 \\
\hline 4 & $\mathrm{~F}$ & 5 & 0,70 & 42 & $\mathrm{~F}$ & 97 & 1,99 & 79 & $\mathrm{~F}$ & 186 & 2,27 \\
\hline 5 & $M$ & 395 & 2,60 & 43 & $M$ & 469 & 2,67 & 80 & $\mathrm{~F}$ & 92 & 1,96 \\
\hline 6 & $\mathrm{~F}$ & 100 & 2,00 & 44 & $M$ & 215 & 2,33 & 81 & $M$ & 61 & 1,79 \\
\hline 7 & $M$ & 368 & 1,65 & 45 & $M$ & 76 & 1,88 & 82 & $M$ & 36 & 1,56 \\
\hline 8 & $\mathrm{~F}$ & 134 & 2,13 & 46 & $M$ & 12 & 1,08 & 83 & $\mathrm{~F}$ & 5 & 0,70 \\
\hline 9 & $M$ & 11 & 1,04 & 47 & $\mathrm{~F}$ & 118 & 2,07 & 84 & $M$ & 237 & 2,37 \\
\hline 10 & $M$ & 183 & 2,26 & 48 & $\mathrm{~F}$ & 276 & 2,44 & 85 & $\mathrm{~F}$ & 5 & 0,70 \\
\hline 11 & $M$ & 37 & 1,57 & 49 & $M$ & 137 & 2,14 & 86 & $\mathrm{~F}$ & 5 & 0,70 \\
\hline 12 & $M$ & 48 & 1,68 & 50 & $\mathrm{~F}$ & 434 & 2,64 & 87 & $\mathrm{~F}$ & 1 & 0,00 \\
\hline 13 & $\mathrm{~F}$ & 51 & 1,71 & 51 & $\mathrm{~F}$ & 134 & 2,13 & 88 & $F$ & 4 & 0,60 \\
\hline 14 & $\mathrm{~F}$ & 124 & 2,09 & 52 & $M$ & 135 & 2,13 & 89 & $\mathrm{~F}$ & 37 & 1,57 \\
\hline 15 & $F$ & 74 & 1,87 & 53 & $M$ & 50 & 1,70 & 90 & $F$ & 7 & 0,85 \\
\hline 16 & $F$ & 81 & 1,91 & 54 & $M$ & 203 & 2,31 & 91 & $F$ & 94 & 1,97 \\
\hline 17 & $F$ & 115 & 2,06 & 55 & $F$ & 102 & 2,01 & 92 & $F$ & 152 & 2,18 \\
\hline 18 & $M$ & 111 & 2,05 & 56 & $M$ & 277 & 2,44 & 93 & $F$ & 104 & 2,02 \\
\hline 19 & $M$ & 136 & 2,13 & 57 & $M$ & 7 & 0,85 & 94 & M & 7 & 0,85 \\
\hline 20 & $M$ & 2 & 0,30 & 58 & $M$ & 476 & 2,68 & 95 & $F$ & 53 & 1,72 \\
\hline 21 & $M$ & 66 & 1,82 & 59 & $F$ & 202 & 2,31 & 96 & $M$ & 133 & 2,12 \\
\hline 22 & $\mathrm{~F}$ & 366 & 2,56 & 60 & $M$ & 216 & 2,33 & 97 & $\mathrm{~F}$ & 38 & 1,58 \\
\hline 23 & $M$ & 139 & 2,14 & 61 & $M$ & 369 & 2,57 & 98 & $F$ & 91 & 1,96 \\
\hline 24 & $M$ & 60 & 1,78 & 62 & $F$ & 98 & 1,99 & 99 & M & 53 & 1,72 \\
\hline 25 & $M$ & 37 & 1,57 & 63 & $F$ & 342 & 2,53 & 100 & $F$ & 16 & 1,20 \\
\hline 26 & $\mathrm{~F}$ & 223 & 2,35 & 64 & $\mathrm{~F}$ & 33 & 1,86 & 101 & $\mathrm{~F}$ & 30 & 1,48 \\
\hline 27 & $M$ & 31 & 1,49 & 65 & $F$ & 301 & 2,48 & 102 & $F$ & 11 & 1,04 \\
\hline 28 & $F$ & 165 & 2,22 & 66 & $M$ & 80 & 1,90 & 103 & $M$ & 69 & 1,84 \\
\hline 29 & $\mathrm{~F}$ & 52 & 1,72 & 67 & $M$ & 85 & 1,93 & 104 & $\mathrm{~F}$ & 200 & 2,30 \\
\hline 30 & $F$ & 17 & 1,23 & 68 & $M$ & 35 & 1,54 & 105 & $M$ & 25 & 1,40 \\
\hline 31 & $F$ & 118 & 2,07 & 69 & $M$ & 52 & 1,72 & 106 & $F$ & 7 & 0,85 \\
\hline 32 & $M$ & 257 & 2,41 & 70 & $F$ & 39 & 1,59 & 107 & $F$ & 122 & 2,09 \\
\hline 33 & $M$ & 48 & 1,68 & 71 & $M$ & 91 & 1,96 & 108 & $M$ & 23 & 1,36 \\
\hline 34 & $M$ & 50 & 1,70 & 72 & $M$ & 233 & 2,37 & 109 & $M$ & 116 & 2,06 \\
\hline 35 & $M$ & 216 & 2,33 & 73 & $F$ & 105 & 2,02 & 110 & $\mathrm{~F}$ & 49 & 1,69 \\
\hline 36 & $F$ & 189 & 2,28 & 74 & $F$ & 153 & 2,18 & 111 & $M$ & 15 & 1,18 \\
\hline 37 & $M$ & 10 & 1,00 & 75 & $F$ & 211 & 2,32 & 112 & $M$ & 22 & 1,34 \\
\hline 38 & $M$ & 70 & 1,85 & & & & & & & & \\
\hline
\end{tabular}


A Tabela 4 apresenta a distribuição das crianças quanto à idade e os dentes (decíduos ou permanentes) que foram utilizados nas microbiópsias.

Tabela 4. Amostra, idade, dente (permanente ou decíduo) que foram usados para as microbiópsias.

\begin{tabular}{|c|c|c|c|c|c|c|c|c|}
\hline Amostra & Idade & Dente & Amostra & Idade & Dente & Amostra & Idade & Dente \\
\hline 1 & 9 & 11 & 39 & 9 & 11 & 76 & 7 & 11 \\
\hline 2 & 5 & 51 & 40 & 8 & 21 & 77 & 8 & 11 \\
\hline 3 & 7 & 11 & 41 & 9 & 11 & 78 & 9 & 11 \\
\hline 4 & 8 & 11 & 42 & 8 & 11 & 79 & 8 & 21 \\
\hline 5 & 7 & 11 & 43 & 8 & 21 & 80 & 8 & 11 \\
\hline 6 & 7 & 11 & 44 & 8 & 11 & 81 & 7 & 61 \\
\hline 7 & 11 & 11 & 45 & 8 & 11 & 82 & 6 & 61 \\
\hline 8 & 8 & 21 & 46 & 8 & 11 & 83 & 8 & 11 \\
\hline 9 & 11 & 11 & 47 & 10 & 11 & 84 & 8 & 11 \\
\hline 10 & 7 & 11 & 48 & 8 & 11 & 85 & 8 & 11 \\
\hline 11 & 10 & 10 & 49 & 8 & 21 & 86 & 8 & 11 \\
\hline 12 & 12 & 21 & 50 & 10 & 11 & 87 & 6 & 51 \\
\hline 13 & 12 & 11 & 51 & 10 & 11 & 88 & 8 & 11 \\
\hline 14 & 9 & 11 & 52 & 10 & 11 & 89 & 9 & 11 \\
\hline 15 & 10 & 11 & 53 & 6 & 51 & 90 & 12 & 11 \\
\hline 16 & 10 & 21 & 54 & 6 & 21 & 91 & 6 & 51 \\
\hline 17 & 9 & 11 & 55 & 7 & 11 & 92 & 9 & 11 \\
\hline 18 & 4 & 51 & 56 & 11 & 11 & 93 & 8 & 53 \\
\hline 19 & 8 & 11 & 57 & 10 & 21 & 94 & 8 & 11 \\
\hline 20 & 7 & 11 & 58 & 8 & 21 & 95 & 11 & 11 \\
\hline 21 & 7 & 51 & 59 & 7 & 11 & 96 & 10 & 11 \\
\hline 22 & 9 & 11 & 60 & 8 & 11 & 97 & 11 & 11 \\
\hline 23 & 9 & 11 & 61 & 7 & 11 & 98 & 7 & 21 \\
\hline 24 & 8 & 11 & 62 & 11 & 11 & 99 & 10 & 11 \\
\hline 25 & 7 & 62 & 63 & 10 & 11 & 100 & 9 & 21 \\
\hline 26 & 8 & 11 & 64 & 6 & 11 & 101 & 7 & 11 \\
\hline 27 & 7 & 11 & 65 & 9 & 11 & 102 & 6 & 61 \\
\hline 28 & 9 & 21 & 66 & 8 & 11 & 103 & 9 & 11 \\
\hline 29 & 8 & 11 & 67 & 7 & 51 & 104 & 9 & 11 \\
\hline 30 & 9 & 11 & 68 & 7 & 11 & 105 & 10 & 11 \\
\hline 31 & 9 & 11 & 69 & 10 & 11 & 106 & 8 & 11 \\
\hline 32 & 8 & 11 & 70 & 8 & 11 & 107 & 9 & 11 \\
\hline 33 & 5 & 51 & 71 & 8 & 21 & 108 & 11 & 11 \\
\hline 34 & 7 & 51 & 72 & 9 & 11 & 109 & 8 & 11 \\
\hline 35 & 9 & 11 & 73 & 11 & 11 & 110 & 9 & 11 \\
\hline 36 & 8 & 21 & 74 & 5 & 51 & 111 & 8 & 11 \\
\hline 37 & 10 & 11 & 75 & 10 & 11 & 112 & 6 & 11 \\
\hline 38 & 9 & 11 & & & & & & \\
\hline
\end{tabular}


Os valores de chumbo (logaritmo de base 10) foram analisados segundo idade (5-12 anos, mediana em 8 anos), gênero (59 meninos e 53 meninas), dentes (decíduos e permanentes) e os diagnósticos neurológicos das 112 crianças.

Não houve correlação entre a idade das crianças e os valores de chumbo (Pearson $r=-0,016 ; p=0,86$ ) também não se observou diferença significativa entre os gêneros (t-test $p=0,55)$ e nem entre dentes permanentes e decíduos (t-test $p=$ 0,11). Do total da amostra, 93\% residiam no estado de São Paulo e 7\% em outros estados (Figura 3A); 94\% residiam em área urbana e 6\% em área rural (Figura B).

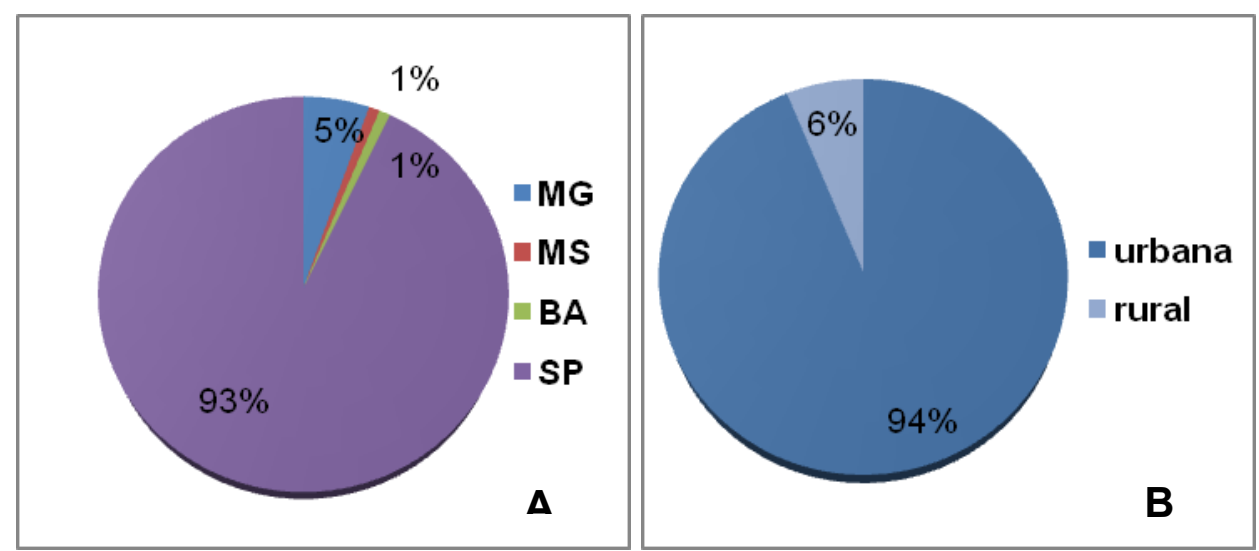

Figura 3. A - Estado de moradia. B - Área rural ou urbana.

Quanto aos cinco grupos com os diferentes diagnósticos neurológicos, os valores de chumbo (logaritmo de base 10) da mediana e média desses grupos estão na Tabela 5.

Tabela 5. Distribuição dos valores de chumbo (logaritmo de base 10) entre os cinco grupos de diagnósticos analisados.

\begin{tabular}{lccccc}
\hline & $\begin{array}{c}\text { Síndrome } \\
\text { motora }\end{array}$ & Epilepsia & Cefaléia & $\begin{array}{c}\text { Dificuldade } \\
\text { escolar }\end{array}$ & $\begin{array}{c}\text { Distúrbio do } \\
\text { Comportamento }\end{array}$ \\
\hline $\mathbf{N}$ & $\mathbf{3 1}$ & $\mathbf{2 5}$ & $\mathbf{1 3}$ & $\mathbf{1 1}$ & $\mathbf{3 2}$ \\
Mín - Max & $0,3-2,6$ & $0,6-2,4$ & $1,0-2,6$ & $1,6-2,5$ & $0,8-2,6$ \\
Q1 - Q3 & $1,4-2,2$ & $0,9-2,0$ & $1,7-2,4$ & $2,1-2,1$ & $1,7-2,3$ \\
Mediana & 1,9 & 1,6 & 1,8 & 2,1 & 1,9 \\
Media & 1,8 & 1,5 & 1,9 & 2,1 & 1,9 \\
Desvio Padrão & 0,5 & 0,6 & 0,5 & 0,2 & 0,4 \\
Erro Padrão & 0,1 & 0,1 & 0,1 & 0,1 & 0,1 \\
\hline
\end{tabular}


Comparando os cinco grupos quanto aos valores do chumbo (logaritmo de base 10) (ANOVA one-way) houve significância com valor de $p=0,004$. 0 pós teste de tukey evidenciou diferença significativa entre o grupo com epilepsia e os grupos com dificuldade escolar e distúrbio de comportamento (Figura 4).

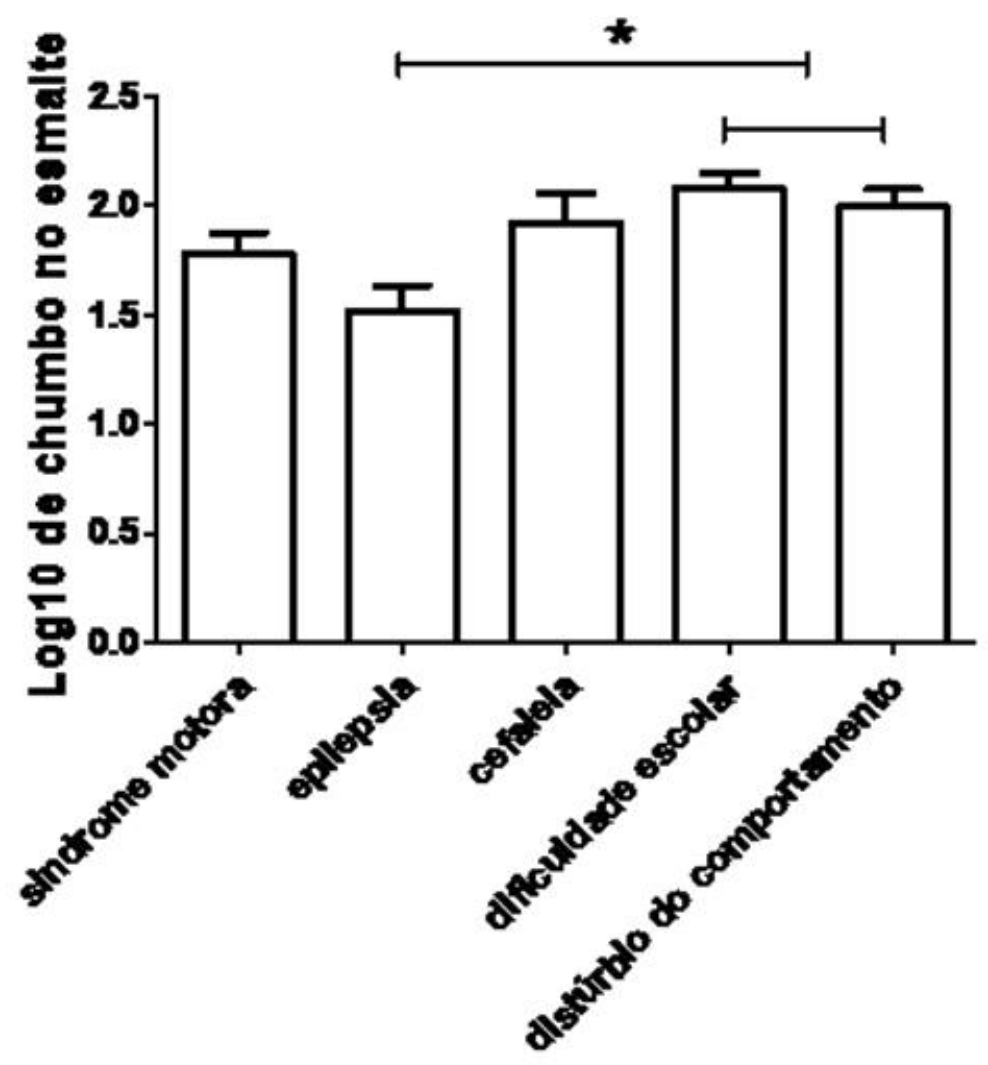

Figura 4. Comparação entre os grupos quanto aos valores de chumbo (logaritmo de base 10) onde $* P<0,05$.

Os cinco grupos foram analisados também de acordo com os fatores de risco de exposição ao chumbo (Tabela 6). Estes fatores de risco eram parte dos questionários que foram respondidos pelos pais ou responsáveis. 
Tabela 6. Fatores de risco, número de casos e valores em porcentagem do total do número de casos em cada grupo.

\begin{tabular}{|c|c|c|c|c|c|c|c|c|c|c|}
\hline & \multicolumn{2}{|c|}{$\begin{array}{c}\text { Síndrome } \\
\text { motora } \\
\mathbf{N}=\mathbf{3 1}\end{array}$} & \multicolumn{2}{|c|}{$\begin{array}{l}\text { Cefaléia } \\
N=13\end{array}$} & \multicolumn{2}{|c|}{$\begin{array}{l}\text { Epilepsia } \\
\qquad \mathrm{N}=25\end{array}$} & \multicolumn{2}{|c|}{$\begin{array}{c}\text { Dificuldade } \\
\text { escolar } \\
\mathbf{N}=11\end{array}$} & \multicolumn{2}{|c|}{$\begin{array}{c}\text { Distúrbio do } \\
\text { comportamento } \\
\mathrm{N}=32\end{array}$} \\
\hline & $\mathrm{N}$ & $\%$ & $\mathrm{~N}$ & $\%$ & $\mathrm{~N}$ & $\%$ & $\mathrm{~N}$ & $\%$ & $\mathrm{~N}$ & $\%$ \\
\hline $\begin{array}{l}\text { Residência } \\
\text { próxima } \\
\text { indústria }\end{array}$ & 4 & $(13,0)$ & 5 & $(38,4)$ & 4 & $(16,0)$ & 2 & $(18,2)$ & 3 & $(9,4)$ \\
\hline $\begin{array}{c}\text { Residência } \\
\text { próxima } \\
\text { indústria } \\
\text { anteriormente }\end{array}$ & 4 & $(13,0)$ & 1 & $(7,7)$ & 1 & $(4,0)$ & 1 & $(9,1)$ & 2 & $(6,2)$ \\
\hline $\begin{array}{l}\text { Morou em } \\
\text { região de uso } \\
\text { agrotóxico }\end{array}$ & 8 & $(25,8)$ & 0 & $(0,0)$ & 4 & $(16,0)$ & 2 & $(18,2)$ & 5 & $(15,6)$ \\
\hline $\begin{array}{l}\text { Pintu ra da } \\
\text { casa durante } \\
\text { ou após } \\
\text { gravidez }\end{array}$ & 10 & $(32,2)$ & 4 & $(30,8)$ & 7 & $(28,0)$ & 1 & $(9,1)$ & 8 & $(25,0)$ \\
\hline $\begin{array}{l}\text { Morou perto } \\
\text { de ferro velho }\end{array}$ & 4 & $(13,0)$ & 2 & $(15,4)$ & 1 & $(4,0)$ & 2 & $(18,2)$ & 6 & $(18,7)$ \\
\hline $\begin{array}{l}\text { Hábito de } \\
\text { comer terra }\end{array}$ & 2 & $(6,45)$ & 2 & $(15,4)$ & 7 & $(28,0)$ & 4 & $(36,4)$ & 6 & $(18,7)$ \\
\hline $\begin{array}{c}\text { Hábito de } \\
\text { brincar com } \\
\text { pilhas }\end{array}$ & 1 & $(3,2)$ & 5 & $(38,4)$ & 5 & $(20,0)$ & 1 & $(9,1)$ & 7 & $(21,9)$ \\
\hline Pegar objetos & 27 & $(87,0)$ & 13 & $(100,0)$ & 22 & $(88,0)$ & 11 & $(100,0)$ & 30 & $(93,7)$ \\
\hline $\begin{array}{l}\text { Leva objetos } \\
\text { à boca }\end{array}$ & 14 & $(45,1)$ & 8 & $(61,5)$ & 17 & $(68,0)$ & 6 & $(54,6)$ & 23 & $(71,9)$ \\
\hline $\begin{array}{c}\text { Profissão dos } \\
\text { pais }\end{array}$ & 12 & $(38,7)$ & 2 & $(15,4)$ & 6 & $(24,0)$ & 4 & $(36,4)$ & 8 & $(25,0)$ \\
\hline
\end{tabular}

O número de respostas positivas às questões sobre fatores de risco variou de zero a oito por criança. Uma criança do grupo com epilepsia apresentou resposta negativa para todos os itens. Ocorreu maior número de crianças que brincam com pilhas no grupo com cefaléia em relação ao grupo com síndrome motora (Teste Exato de Fisher, $p=0,002)$, e tendência em relação ao grupo com dificuldade escolar (Teste Exato de Fisher, $p=0,06$ ).

Não houve correlação entre o número cumulativo de fatores de risco por criança e os valores de chumbo (Pearson $r=-0,0886 p=0,35$ ).Na amostra geral os fatores de risco não evidenciaram diferenças significativas, em nível de $5 \%$, quanto 
aos valores de chumbo entre os casos positivos $(p=0,53)$, nem entre os negativos $(p=0,99)$ e nem entre ambos, comparando-se cada um dos fatores. O mesmo ocorreu na análise intragrupo para cada um dos cinco grupos diagnósticos e na análise entre os grupos. 


\section{DISCUSSÃO}

A técnica da microbiópsia de esmalte, proposta por Brudevold et al. em 1975 e modificada por Gomes et al. em 2004, possibilita a determinação da concentração de chumbo presente no esmalte de dentes decíduos e permanentes. Tal procedimento, além de pouco invasivo, indolor, de baixo custo e de fácil execução, mostrou-se adequado para estudos epidemiológicos que frequentemente utilizam grandes amostras populacionais (Costa de Almeida et al., 2007).

A utilização da técnica da microbiópsia de esmalte no presente trabalho mostrou-se útil para coletar amostras de esmalte dental, pois além de ser uma técnica de fácil execução, é corroborada por trabalhos na literatura para comprovar a sua eficiência. A microbiópsia de esmalte foi utilizada in vivo como amostra para dosagem de chumbo tanto em dentes permanentes (Brudevold et al., 1975; Cleymaet et al., 1991 a, b, c, d), quanto em decíduos (Gomes et al., 2004; Costa de Almeida et al., 2007; Costa de Almeida et al., 2008).

Não foram completamente elucidados os mecanismos envolvidos na incorporação de chumbo no esmalte superficial, porém diversos trabalhos demonstraram diferenças muito claras entre populações de cidades notoriamente contaminadas e cidades sem histórico de contaminação ambiental descrito (Gomes et al., 2004; Costa de Almeida et al., 2007).

Recentemente a morfologia das microbiópsias foi estudada por meio de Microscopia Eletrônica de Varredura e Microscopia de Luz Polarizada (Costa de Almeida et al, 2009a). Nesse trabalho verificou-se que a microbiópsia não desmineraliza o esmalte em profundidade. Além disso, pela análise da birrefringência 
do esmalte, pôde ser demonstrado que não ocorre perda mineral no esmalte devido à utilização do ácido no procedimento da microbiópsia do esmalte. Esses achados corroboram para a afirmação de que a microbiópsia não é um procedimento invasivo, nem destrutivo.

Sabe-se que os mecanismos de formação e mineralização do esmalte e da dentina são bem diferentes. Sabe-se que durante a deposição da matriz do esmalte apenas $30 \%$ dele é mineralizado, enquanto que o restante do volume de mineral é adquirido depois que toda a sua espessura foi depositada (Bercovitz et al., 1992). Estudos realizados em fetos humanos e dentes decíduos (Deutsch e Shapiro, 1987) evidenciaram que o esmalte presente ao nascimento não é completamente mineralizado e adquire um volume substancial de minerais no período pós natal. Diante disso, é possível que os componentes inorgânicos depositados no período pré natal, incluindo os depósitos de chumbo, podem ser particularmente adquiridos também no período pós natal (Arora et al., 2006).

Parâmetro importante a ser considerado é a profundidade de biópsia. Quando correlacionamos a concentração de chumbo com a profundidade de microbiópsia constatamos que existe uma correlação significante e negativa, ou seja, à medida que a profundidade da microbiópsia aumenta a concentração de chumbo diminui. Esse achado foi descrito por vários autores para dentes permanentes (Brudevold et al., 1975, 1977; Purchase e Fergusson, 1986; Cleymaet et al., 1991 a, b, c, d) e dentes decíduos (Gomes et al., 2004; Costa de Almeida et al., 2007). Baseado nisso, é recomendável que façamos uma comparação entre microbiópsias de profundidades similares. A profundidade de biópsia sofre influência de vários fatores que não podem ser controlados pelo indivíduo que está executando a técnica. Diferenças na 
temperatura ambiente, evaporação da solução ácida e maior resistência do dente são alguns fatores que podem afetar a profundidade de microbiópsia (Cleymaet et al., 1991 d).

Sabendo-se então da relação entre concentração de chumbo e a profundidade de biópsia, concluímos que o ideal seria colocar os dados de chumbo referentes a cada amostra em uma mesma profundidade. Pensando nisso, tentamos estabelecer uma equação que pudesse prever qual a concentração de chumbo encontrada em uma dada profundidade. Para fazer os cálculos foi necessário realizar uma regressão linear log-log. Para as análises, plotamos os dados da profundidade de biópsia em $\mu \mathrm{m}$ no eixo $x$ e os dados da concentração de chumbo no esmalte em $\mu \mathrm{g} / \mathrm{g}$ em y. Esses dados foram transformados em logaritmo natural. A partir desses dados, realizou-se a regressão linear, o qual nos forneceu o valor de $\beta$ e a que estão relacionados com a concentração de chumbo e a profundidade de biópsia na equação $(y=a \times \beta$, onde y é a concentração de chumbo e $x$ a profundidade de biópsia). Finalmente com os valores de $\beta$ e a e utilizando-se a equação da reta foi possível fazer esse cálculo.

Com relação à exposição ao chumbo o principal perigo reside nos produtos destinados às crianças. Alguns brinquedos podem conter chumbo em suas pinturas e as crianças, sobretudo as de menor idade, têm o hábito de colocar objetos na boca. Isso pode ser grave, porque a absorção intestinal de uma criança é muito mais rápido que em um adulto. Além disso, o sistema nervoso central em desenvolvimento é muito mais vulnerável a agentes tóxicos do que o sistema nervoso maduro (Lidsky e Schneider, 2003). 
Podemos observar que nessa amostra, a frequência de crianças em risco de exposição aos fatores analisados foi baixa, excetuando-se o fato de que a maioria apanhava objetos e levava à boca. Não foi possível estabelecer uma relação entre os fatores de risco e os resultados obtidos nos grupos com os diferentes diagnósticos, sugerindo que as quantidades de chumbo encontradas podem ser dependentes de susceptibilidades individuais, ou presença de fatores facilitadores de expressão do chumbo no esmalte, como baixo nível de hemoglobina. Assim caberia um estudo mais aprofundado, como verificação de níveis de hemoglobina, cálcio e zinco (Wright et al., 1998, 1999, 2003; Bradman et al., 2001) e ainda estudos de polimorfismos (Montenegro et al., 2006b).

Outra abordagem corresponderia ao questionário sobre os fatores de risco de exposição ao chumbo. O modelo sim/não de respostas às questões seria insuficiente para a análise, cabendo abrirem subitens em cada uma das questões para uma análise qualitativa e quantitativa.

Pesquisas em Ribeirão Preto indicam baixo nível de chumbo em escolares, comparados a amostras de pacientes sabidamente contaminados (Costa de Almeida et al., 2007). O interesse na avaliação de crianças com problemas neurológicos surge de questionamentos sobre a relação desse metal com o tipo de quadro neurológico, seu efeito sobre os sinais clínicos da doença e as particularidades dessas crianças quanto ao risco de exposição ao chumbo. Na presente amostra foram detectados níveis de chumbo com valores significativamente diferentes em grupos distintos.

O significado dessa diferença pode ser buscado na observação de que os maiores valores de chumbo encontraram-se justamente nos grupos com alterações comportamentais e dificuldade escolar, corroborando a literatura (Needleman et al., 
1979, 1990; Bellinger et al., 1994; Lanphear et al., 2000; Canfield et al., 2003; Bellinger, 2004; Chiodo et al., 2004; Järup, 2003). Surge assim a questão sobre qual seria o nível seguro de chumbo, limite aceitável para a integridade da função neural, como valorizar fontes de exposição ao chumbo, quais parâmetros individuais de susceptibilidade seriam estudados e qual seria a conduta médica a ser tomada frente a esses achados.

No entanto, se por um lado, limites máximos no teor de chumbo representam um desafio, o menor teor de chumbo no grupo com epilepsia é um achado, que também suscita indagações. Algumas variáveis no estudo do paciente com epilepsia poderiam ser exploradas como redutoras de chumbo no esmalte, por exemplo, interação com antiepilépticos e características de crises, como sua frequência, duração, tipo e localização de lesão, se em áreas de maior demanda metabólica ou envolvimento de astrócitos nas sinapses e sua relação com cálcio. Os astrócitos são considerados os mais importantes depositários de chumbo no tecido nervoso (Sierra et al., 1991; Tiffany-Castiglioni, 1993), e o chumbo tem similaridade com o cálcio, podendo ser competitivo nas reações metabólicas.

O autismo é um transtorno do desenvolvimento que prejudica a comunicação, tanto verbal e não verbal e interações sociais e está associado com um anormal e restrito leque de interesses. Embora os sintomas geralmente desenvolvam-se sem causa etiológica clara, alguns casos estão associados a distúrbios ou condições que afetam negativamente o desenvolvimentodo do cérebro. $O$ chumbo é uma neurotoxina na qual o cérebro em desenvolvimento é altamente vulnerável. Além disso, intoxicações por chumbo em crianças são conhecidas por afetar negativamente os sistemas cerebrais implicados no cognitivo, comunicação e funcionamento social. Diante do exposto Lidsky e Schneider (2005) em seu artigo 
apresentaram dois relatos de casos de crianças que, durante os períodos de graves intoxicações por chumbo desenvolveram autismo ou sintomas autísticos. Em nossa amostra duas crianças do grupo com distúrbios do comportamento tinham autismo definido.

Considerando o grande número de crianças com problemas neurológicos que levam objetos à boca, atenção especial deve ser dispensada ao risco de exposição ambiental ao chumbo e os resultados mais elevados em crianças com deficiência mental. Vale salientar que as principais fontes de contaminação devem ser incluídas em anamnese clínica em nível primário de atendimento, como uma medida no sentido da vigilância desse risco, desde a consulta pré-natal (Paoliello et al., 2002; Segura-Muñoz et al., 2003; Célere e Segura-Muñoz, 2007), lembrando que pode haver associação dessa exposição com abortos (Lamadrid-Figueroa et al., 2007). Assim, sugere-se estabelecer uma relação de fatores de risco: 1- terra - proximidade de lixões, a poeira, que pode contaminar a água de caixas de água abertas, canos de água antigos feitos de chumbo, soldas. É preocupante a observação em Ribeirão Preto-SP, de que a água em área supostamente sem risco, que abastece o Campus Universitário da USP contém níveis de chumbo 40\% acima dos valores considerados não tóxicos (Segura-Muñoz et al., 2003), 2 - Alimentos de origem próxima a lixões, sucatas, e indústrias de fundição, 3 - vapores de gasolina com chumbo - desde 1989 a Petrobrás deixou de adicionar chumbo na gasolina, vindo a substituí-lo pelo álcool para melhorar a octanagem, 4 - tintas e chumbo inorgânico - verificar contato com fabricação de cerâmicas, pisos e louças, lacre de garrafas de vinho, cristais e vidros, tintas para impressão de jornais e revistas; indústrias de soldas de tubulações e cabos elétricos; tubulações de água feitos de chumbo; fundições de cobre, zinco e 
bronze; fabricação de plásticos (PVC) e equipamentos eletrônicos (soldas); brinquedos (tinta e chumbinhos - não se sabe o percentual de retorno do recall feito pela Mattel, de 847 mil brinquedos chineses). Devido à descoberta de contaminação de muitas crianças por chumbo após terem comido lascas de tinta seca, na década de 1970 os governos de alguns países impuseram restrições ao conteúdo de chumbo nas tintas de uso doméstico, limitando-o a cerca de 0,5\%. No Brasil, em 2005 a Comissão de Desenvolvimento Econômico, Indústria e Comércio aprovaram o Projeto de Lei $5334 / 05$, que fixa em $0,06 \%$ a quantidade máxima permitida de chumbo na fabricação de tintas e vernizes. Munição para tiro; reparos em radiadores e baterias de carros; moedas; e até em cosméticos, além de materiais para a pesca. Em 2007, no Brasil, a Comissão de Meio Ambiente e Desenvolvimento Sustentável aprovou o Projeto de Lei 4076/04 que proíbe o uso de chumbo em materiais de pesca. No Vale da Ribeira-SP, níveis altos de chumbo relacionaram-se com área residencial próxima a refinarias de chumbo (OR 10,38 e 95\% Cl 4,86-23,25), antiga ocupação do pai em áreas de risco (OR 4,07; 95\% Cl 1,82-9,24) e gênero masculino (OR 2,60; 95\% Cl 1,24-5,62) (Paoliello et al., 2002).

Needleman et al(1972) foi um dos pioneiros na luta para o reconhecimento dos efeitos danosos desse metal e apresentaram os primeiros estudos em crianças americanas. Em outro estudo observaram que mais de 3000 crianças frequentando primeira e segundas séries foram expostas a chumbo no passado, em análise da concentração de chumbo nos dentes, e que variáveis neuropsicológicas, nível intelectual, processamento auditivo central e escores em eletroencefalograma foram piores em crianças com os mais altos níveis de chumbo (Needleman et al., 1983).

Com as medidas para redução das taxas de chumbo na gasolina e nas tintas 
houve redução do número de crianças intoxicadas, mas os riscos das residências com pinturas antigas, anteriormente ao período de 1978 ainda representam séria ameaça para as crianças americanas. Estudos em diversas partes do mundo apontam para a relação entre níveis altos de chumbo no sangue e alteração no desenvolvimento infantil. Em meta-análise de 24 estudos sobre relação entre níveis de chumbo e quociente de desenvolvimento ou inteligência infantil, aponta que plumbemia mesmo abaixo de $10 \mu \mathrm{g} / \mathrm{dL}$ podem causar danos. Tais achados têm sido corroborados por dados recentes (Needleman e Gatsonis, 1990). Em Cincinati registraram escores de inteligência reduzindo proporcionalmente ao aumento das taxas de chumbo, mesmo naquelas crianças com níveis abaixo de $10 \mu \mathrm{g} / \mathrm{dL}$. Entre 276 com 6 meses de idade houve redução de 11 pontos no quociente de desenvolvimento e redução de 5 pontos a cada $10 \mu \mathrm{g} / \mathrm{dL}$ a mais (Lanphear et al., 2005). Assim como nestes, em vários outros estudos tem sido observado que o chumbo não somente interfere na maturação de funções cognitivas já estabelecidas, mas também afeta aquelas em desenvolvimento no presente e ainda as que vão surgir como a capacidade de organização, planejamento, senso crítico e de estabelecer limites, inibição, raciocínio numérico (Johann et al., 2006).

Alguns estudos têm apontado relação entre níveis altos de chumbo na infância e criminalidade na juventude (Denno, 1990; Dietrich 2001). Recentemente extensa pesquisa envolvendo dados forenses demonstra forte associação entre níveis elevados de chumbo em crianças no período pré-escolar e criminalidade de vários tipos, analisando as tendências internacionais das taxas de criminalidade ao longo de várias décadas desde 1940, evidenciando, por análise de regressão múltipla, a forte relação entre períodos críticos de elevado nível de exposição ao chumbo (pinturas 
em casas antigas e gasolina) e as maiores taxas de criminalidade, enquanto o contrário também ocorreu principalmente no período após as medidas de retirada do chumbo da gasolina (Nevin, 2007).

Diante de tantas sequelas graves as autoridades têm motivos suficientes para priorizar políticas públicas que visem o controle da contaminação ambiental, particularmente pelo chumbo. Alguns países desenvolvidos têm discutido sobre a relação da intoxicação por chumbo e as perdas econômicas de um país. Quando se fala de perdas econômicas podemos dizer que esta não está somente relacionada com os gastos envolvidos com o tratamento dos intoxicados, mas também com o desenvolvimento de uma dada economia. Isto pode ser mais bem compreendido quando constatamos que após a redução do chumbo na gasolina, por exemplo, calculou-se que houve um ganho de cerca de 2,2 - 4,7 no QI e o aumento do QI da população está diretamente relacionado com o sucesso econômico de um país. Sabendo disso, algumas políticas de saúde pública lançaram medidas para proteger a população dos riscos e evitar o envenenamento individual e nacional com o intuito de prevenir futuras perdas econômicas. O governo apoiou campanhas de educação visando informar o público sobre os perigos da exposição ao chumbo. Tais iniciativas públicas para a prevenção primária já existem em países desenvolvidos (www.cdc.gov,www.fda.gov, www.epa.gov), no entanto, muito pouco tem sido feito no Brasil, onde a grande maioria da população não está consciente dos perigos do envenenamento por chumbo.

Esse é um dos problemas que existe no Brasil, onde há poucos dados sobre exposição ao chumbo e, os que existem são esporádicos e realizados em uma pequena amostra de indivíduos. Apesar das medidas de controle estabelecidas por 
lei, intoxicações agudas e crônicas por chumbo ainda acontecem no Brasil (Paoliello et al., 2002). Nos últimos anos vários episódios de contaminação por chumbo, principalmente em crianças, têm surpreendido algumas cidades industrializadas (Araujo et al., 1999). Isso revela a pouca preocupação no Brasil com o controle da contaminação por um metal pesado cujos efeitos deletérios à saúde humana são conhecidos desde a antiguidade. Os poucos estudos de contaminações por chumbo no Brasil evidenciam ausência de adoção de medidas de controle das contaminações, falta de conhecimento da real situação de contaminação por chumbo no país e a carência de um sistema de vigilância epidemiológica.

Dentre as dificuldades de se manter um sistema de vigilância epidemiológica dos níveis de chumbo numa população está a forma de detecção do mesmo. Sangue, saliva e dentes têm sido preconizados para utilização em análises em estudos epidemiológicos, e cada um deles oferece informações diferentes sobre a história de contaminação pelo chumbo.

A constatação de que níveis inclusive abaixo de $10 \mu \mathrm{g} / \mathrm{dL}$ podem levar a futuras deficiências cognitivas e comportamentais em crianças ampliam muito a necessidade de investigação dos seus efeitos sobre o sistema nervoso e justifica a busca de melhores técnicas de detecção do chumbo no organismo humano, sua relação temporal com as alterações observadas, seu mecanismo de comprometimento dos diversos órgãos, bem como os fatores genéticos envolvidos na expressão de sua sintomatologia.

Este fato vem de encontro com a informação que neste ano de 2012, mais precisamente em janeiro, o Comitê para Aconselhamento do CDC (Centers for Disease Control's And Prevention) sobre Prevenção de Intoxicação Infantil por 
Chumbo aprovou uma resolução recomendando a diminuição do limite mínimo de ação para valores de chumbo no sangue de $10 \mathrm{ug} / \mathrm{dL}$ para 5 ug/dl (ACCLPP, 2012). Esta informação vem mais uma vez reafirmar a necessidade de monitoramento de populações, aos efeitos deletérios do chumbo mesmo em baixos níveis. 


\section{CONCLUSÃO}

O presente estudo demonstrou que não houve correlação entre a idade das crianças e os valores de chumbo, não se observou diferença significativa entre os gêneros masculinos e femininos, e também não houve diferença entre os dentes decíduos e permanentes.

Comparando os cinco grupos quanto aos valores do chumbo houve significância com valor de $p=0,004$ entre o grupo com epilepsia e os grupos com dificuldade escolar e distúrbio do comportamento.

$\mathrm{Na}$ análise da distribuição dos casos quanto a fatores de risco de exposição ao chumbo, não se observou diferença significativa entre os grupos com distúrbio do comportamento ou dificuldade escolar e o grupo com epilepsia. Houve maior concentração de crianças que brincam com pilhas no grupo com cefaléia em relação a dois outros grupos, sendo a diferença significativa com o grupo de distúrbios motores. Não ficaram evidentes diferenças significativas, em nível de $5 \%$, quanto aos valores de chumbo entre os casos com respostas positivas, negativas ou comparando esses dois grupos de respondentes. O mesmo ocorreu na análise dos grupos segundo diagnóstico neurológico, intra-grupo e intergrupos.

Assim, maiores valores de chumbo no esmalte superficial em grupos de crianças com dificuldade escolar e distúrbio do comportamento em relação àquele com epilepsia, e ainda, os achados de que os fatores ambientais de risco estudados não tiveram relação com as diferenças observadas entre esses grupos, suscitam indagações e necessidade de aprofundamento em pesquisas sobre os efeitos danosos do chumbo no tecido neural, mesmo quando se trata de uma população que vive em áreas consideradas sem risco ambiental e com valores de chumbo no sangue (quando são medidos, o que não é o caso deste estudo) abaixo do limite de intervenção. 


\section{REFERÊNCIAS}

Advisory Committee on Childhood Lead Poisoning Prevention. Low Level Lead Exposure Harms Children: A Renewed Call for Primary Prevention 2012. Disponível em:http://www.cdc.gov/nceh/lead/ACCLPP/Final Document 010412.pdf.

Agency for Toxic Substances and Disease Registry. Toxicological Profile for Lead. Washington, D.C., U.S.Department of Health \& Human Services; 2005.

Agency for Toxic Substances and Disease Registry.Toxicological profile for lead. US Department of Health and Human Services Public Health Service; 1999.

Altshuller L F, Halak D B, Landing B H, Kehoe R A. Deciduous teeth as an index of body burden of lead. J Pediatr 1962;60:224-229.

Amaral, JH, Rezende, VB, Quintana SM ; Gerlach RF, Barbosa, F, Tanus-Santos, JE. The Relationship between Blood and Serum Lead Levels in Peripartum Women and their Respective Umbilical Cords. Basic \& Clinical Pharmacology \& Toxicology 2010;107:971-975.

Amorin LCA. Os biomarcadores e sua aplicação na avaliação da exposição aos agentes químicos ambientais. Ver Bras Epidemiol 2003:6: 1-13.

Anttila, A. Lead content of deciduous tooth enamel from a high-radon area. Acta Odontol Scand. 45,283-288, 1987.

Araujo U, Pivetta F, Moreira J: Avaliação da exposição ocupacional ao chumbo: proposta de uma estratégia de monitoramento para prevenção dos efeitos clínicos e subclínicos. Cadernos de Saúde Publica 15:123, 1999.

Arora M, Chan SW, Ryan CG, Kennedy BJ, Walker DM. Spatial distribution of lead in enamel and coronal dentine of wistar rats. Biol Trace Elem Res. 2005;105(1-3): 15970.

Arora, M., Kennedy, B. J., Elhlou, S., Pearson, N.J., Walker, D.M., Bayl, P, Chan S.W.Y. Spatial distribution of lead in human primary teeth as a biomarker of pre- and neonatal lead exposure. Sci Total Environ 2006; 371:55-62.

Attramadal A, Jonsen J. The content of lead, cadmium, zinc and copper in deciduous and permanent human teeth. Acta Odontol Scand 1976; 34:127-131.

Audesirk, G. Effects of lead exposure on the physiology of neurons. Progress in Neuro-biology 1985;24:199-231.

Baker EL, White RF, Pothier L, Berkey CS, Dinse GE, Travers PH, Harley JP, Feldman RG. Occupational lead neurotoxicity: improvement in behavioural effects after reduction of exposure. $\mathrm{Br}$ J Ind Med 1985; 42(8): 507-16. 
Barbosa FJr, Tanus-Santos JE, Gerlach RF, Parsons PJ. A critical review of biomarkers used for monitoring human exposure to lead: advantages, limitations, and future needs. Environ Health Perspect 2005; 113(12): 1669-74.

Barry, PS: Concentrations of lead in the tissues of children. $\mathrm{Br} \mathrm{J}$ Ind Med 1981; 38:61.

Bellinger $\mathrm{D}, \mathrm{Hu} \mathrm{H}$, Titlebaum L, Needleman HL. Attentional correlates of dentin and bone lead levels in adolescents. Arch Environ Health 1994; 49(2): 98-105.

Bellinger D,Leviton A, Waterman C, Needleman L, Rabinowitz M. Longitudinal analyses of prenatal and postnatal lead exposure and early cognitive development. $\mathrm{N}$ Engl J Med 1987; 316(17):1037-43.

Bellinger DC, Stiles KM, Needleman HL. Low-level lead exposure, intelligence and academic achievement: a long-term follow-up study. Pediatrics 1992; 90(6): 855-61.

Bellinger DC. Lead. Pediatrics 2004; 113(4 Suppl): 1016-22.

Bercovitz K, Laufer D. Systemic lead absorption in human tooth roots. Arch Oral Biol 1992;37: 385-387.

Bergdahl IA, Skerfving S. Biomonitoring of lead exposure - alternatives to blood. J Toxicol Environ Health A 2008;71:1235-43.

Bergdahl IA, Vahter M, Counter SA, Schütz A, Buchanan LH, Ortega F, Laurell G, Skerfving S: Lead in plasma and whole blood from lead-exposure children. Environ Res Sect 1999;80:25.

Bernard SM. Should the Centers for Disease Control and Prevention's Childhood Lead Poisoning Intervention Level Be Lowered? Am J Public Health 2003; 93:1253-60

Binns HJ, Campbell C, Brown MJ. Interpreting and managing blood lead levels of less than $10 \mathrm{microg} / \mathrm{dL}$ in children and reducing childhood exposure to lead:recommendations of the Centers for Disease Control and Prevention Advisory Committee on Childhood Lead Poisoning Prevention. Pediatrics. 2007; 120(5):128598.

Bradman A, Eskenazi B, Sutton P, Athanasoulis M, Goldman LR. Iron deficiency associated with higher blood lead in children living in contaminated environments.Environ Health Perspect. 2001; 109(10): 1079-84.

Brudevold F, Aasenden R, Srinivasian BN, Bakhos $Y$ : Lead in enamel and saliva, dental caries and the use of enamel biopsies for measuring past exposure to lead. J Dent Res 1977;56:1165.

Brudevold F, Reda A, Aasenden R, Bakhos Y: Determination of trace elements in surface enamel of human teeth by a new biopsy procedure. Arch Oral Biol $1975 ; 20: 667$. 
Brudevold F, Steadman LT: The distribution of lead in human enamel. J Dent Res $1956 ; 35: 430$.

Burbure C, Buchet JP, Leroyer A, Nisse C, Haguenoer J-M, Mutti A et al. Renal and Neurologic Effects of Cadmium, Lead, Mercury, and Arsenic in Children: Evidence of Early Effects and Multiple Interactions at Environmental Exposure Levels. Environ Health Perspect 2006;114:584-90.

Cake KM, Bowins RJ, Vaillancourt C, Gordon CL, McNutt RH, Laporte R et al.:Partition of circulating lead between serum and red cells is different for internal and external sources of lead. Am J Ind Med 1996;29:440.

Calabrese EJ, Stanek EJ, James SM: Soil ingestion: a concern for acute toxicity in clildren. Environ Health Perspect 1997;105:1354.

Calabrese EJ. Expanding the reference dose concept to incorporate and optimize beneficial effects while preventing toxic responses from nonessential toxicants. Regul Toxicol Pharmacol 1996; 24(1 Pt 2): S68-75.

Canfield RL, Henderson CR Jr, Cory-Slechta DA, Cox C, Jusko TA, Lanphear BP. Intellectual impairment in children with blood lead concentrations below 10 microg per deciliter. N Engl J Med. 2003; 348(16): 1517-26.

Carlisle JC, Dowling KC, Siegel DM, Alexeeff GV. A blood benchmark of assessing risks from chilhood lead exposure. Journal of Envionmental Science and Health. 2009a; 44, 1200-1208.

Célere MS, Oliveira AS, Segura-Munõz SI. Metais presentes no chorume coletado no aterro sanitário de Ribeirão Preto, São Paulo, Brasil, e sua relevância para saúde pública. Cad Saúde Pública 2007; 23:939-47.

Centers for Disease Control and Prevention. Preventing Lead Poisoning in Young Children. Atlanta, GA: Centers for Disease Control and Prevention; 1991.

Centers for disease control and prevention. Screening young children for lead poisoning: guidance for state and local public health officials. Atlanta: USDHHS-CDC, 1997.

Chiodo LM, Jacobson SW, Jacobson JL. Neurodevelopmental effects of postnatal lead exposure at very low levels. Neurotoxicol Teratol 2004; 26(3): 359-71.

Cicuttini FM, Fairley CK, McNeil JJ, Taylor ER: The public health problem of environmental lead exposure. Med J Aust 160:173, 1994.

Cleymaet, R., Bottenberg, P., Retief, D.H., Slop, D., Michotte, Y., Coomans, D. In vivo use of a dual acid etch biopsy for the evaluation of lead profiles in human surface enamel. Caries Res 1991a; 25,256-263. 
Cleymaet, R., Bottenberg, P., Slop, D., Clara, R., Coomans, D., Study of lead and cadmium content of surface enamel of schoolchildren from an industrial area in Belgium. Community Dent Oral Epidemiol 1991b;19,107-111.

Cleymaet, R., Collys, K., Retief, D.H., Michotte, Y.,Slop, D., Taghon, E., Maex, W., Coomans, D. Relation between lead in surface tooth enamel, blood, and saliva from children residing in the vinicity of a non-ferrous metal plant in Belgian 1991e;48, 702-9.

Cleymaet, R., Quartier, E., Slop, D., Retief, D.H., Smeyers-Verbeke, J., Coomans, D., Model for assessment of lead content in human surface enamel. J Toxicol Environ Health 1991c; 32,111-127.

Cleymaet, R., Retief, D.H., Quartier, E., Slop, D., Coomans, D., Michotte, Y. A comparative study of the lead and cadmium content of surface enamel of Belgian and Kenyan children. Sci Total Environ 1991d;104,175-189.

Coon T, Miller M, Shirazi F, Sullivan J,Lead Toxicity in a 14-Year-Old Female With Retained Bullet Fragments Pediatrics 2006;117:227-230.

Cooper WC, Wong O, Kheifets L. Mortality among employees of lead battery plants and lead-producing plants, 1947-1980. Scand J Work Environ Health 1985;11:33145.

Costa de Almeida GR, de Freitas CU, Barbosa F Jr, Tanus-Santos JE, Gerlach RF. Lead in saliva from lead-exposed and unexposed children. Sci Total Environ 2009 (a); 407:1547-50.

Costa de Almeida GR, de Souza Guerra C, Tanus-Santos JE, Barbosa F Jr, Gerlach RF. A plateau detected in lead accumulation in subsurface deciduous enamel from individuals exposed to lead may be useful to identify children and regions exposed to higher levels of lead. Environ Res 2008; 107(2): 264-70.

Costa de Almeida GR, Molina GF, Meschiari CA, Barbosa de Sousa F, Gerlach RF. Analysis of enamel microbiopsies in shed primary teeth by Scanning Electron Microscopy (SEM) and Polarizing Microscopy (PM). Sci Total Environ 2009b;407(18):5169-75.

Costa de Almeida GR, Saraiva MCP, Barbosa F, Krug FJ, Cury JA, Sousa MLR, Buzalaf MAR, Gerlach RF. Differences in lead content of deciduous teeth surface enamel sampled in vivo from children living in an apparently not-contamined and in a leadcontaminated area: a contribution for the development of an accessible marker of lead exposure in children. Environ Res 2007;104(3):337-45.

Costa de Almeida GR, Tavares CFF, Souza AM, Sousa TS, Funayama CAR, Barbosa F Jr, Tanus-Santos JE, Gerlach RF. Whole blood, serum, and saliva lead concentrations in 6- to 8-year-old children. Sci Total Environ 2010;408:1551-1556.

De Genaro LD. Lead and the developing nervous system. Growth Dev Aging 2002;66(1):43-50. 
Denno DW. Biology and Violence. Cambridge University Press, New York, 1990.

Deutsch D, Shapiro L. Pattern of mineral uptabe in the developing human decíduos enamel. J Craniofac Genetic Dev Biol 1987;7:137-43.

Dietrich K, Ris M, Succop P, Berger O, Bornschein R. Early exposure to lead and juvenile delinquency. Neurotoxicol Teratol 2001;23:511-18.

Dórea JG, Donangelo, CM. Early (in uterus and infant) exposure to Mercury and lead. Clinical Nutrition 2006;25(3):369-376.

Ericson JE. Enamel lead biomarker for prenatal exposure assessment. Environ Res 87:136-140, 2001.

Ettinger AS, Téllez-Rojo MM, Amarasiriwardena C, González-Cossío T, Peterson KE, Aro $A$ et al. Levels of lead in breast milk and their relation to maternal blood and bone lead levels at one month postpartum. Environ Health Perspect 2004;112(8):926-31.

Fergusson DM, Fergusson JE, Horwood $\mathrm{D}$, Kinzett NG. A longitudinal study of dentine lead levels, intelligence, school performance and behaviour. Part I. Dentine lead levels and exposure to environmental risk factors. J Child Psychol Psychiatry 1988; 29(6): 781-92.

Fergusson JE, Purchase NG, The analysis and levels of lead in human teeth: a review. Environ Pollut 1987; 46(1): 11-44.

Fiske $\mathrm{CH}$, Subbarow Y. The colorimetric determination of phosphorus. J Biol Chem 1925; 66:375-400.

Fleischer N, Mouw R, Vander AJ. Chronic effects of lead on renin and renal sodium excretion. J Lab Clin Med 1980; 95: 759-70.

Fullmmer CW, Edelstein S, Wasserman RII. Lead-binding properties of intestinal calcium-binding proteins. J Biol Chem 1985;260:6816-6819.

Gidlow DA. Lead toxicity. Occup Med (Lond) 2004;54:76-81.

Gil F, Pérez ML, Facio A, Villanueva E, Tojo R, Gil A. Dental lead levels in the Galician population, Spain. Sci Total Environ 1994; 156(2): 145-50.

Gilbert SG, Rice DC. Low-level lifetime lead exposure produces behavioral toxicity (spatial discrimination reversal) in adult monkeys. Toxicol Appl Pharmacol 1987;91(3): 484-90.

Goldman LR. Lead regulation. Science 1998; 282(5395): 1825-7.

Gomes VE, Sousa M LR, Barbosa F, Krug FJ, Saraiva MCP, Cury JA, Gerlach RF: In vivo studies on lead content of deciduous teeth superficial enamel of pre-school children. Sci Total Environ 2004;320:25. 
González-Cossío T, Peterson KE, Sanín LH, Fishbein E, Palazuelos E, Aro A, Goyer R A, Clarkson T W. Toxic effects of metals. In: Cassaret, Doull's. Toxicology: the basic science of poisons. $6^{\text {rd }}$ ed. McGraw-Hill Professional 2001; 23:811-867.

Goyer RA, Cherian MG, Jones MM, Reigart JR. Role of chelating agents for prevention, intervention, and treatment of exposures to toxic metals. Environ Health Perspect 1995; 103(11): 1048-52.

Goyer RA, Clarkson TW. Toxic effects of metals. In: Casarett \& Doull's Toxicology: The Basic Science of Poisons. New York: McGraw Hill; 2001. p.811-837.

Greninger D, Kolionitsch V, Kline CK. Lead Chemicals. New York:International Lead and Zinc Organization 1978.

Grobler SR, Theunissen FS, Kotze TJ. The relation between lead concentration in human dental tissues and in blood. Arch Oral Biol 2000; 45:607-609.

Gulson BL, Mahaffey KR, Jameson CW, Mizon KJ, Korsch MJ, Cameron MA, Eisman EA. Mobilization of lead from the skeleton during the postnatal period is even larger during pregnancy. J Lab Clin Med 1998a;131:324-329.

Gulson BL, Mahaffey KR, Mizon KJ, Korsch MJ, Cameron MA, Vimpani G. Contribution of tissue lead to blood lead in adult female subjects based on stable lead isotope methods. J Lab Clin Med 1995; 125:703-712.

Gulson BL. Tooth analyses of sources and intensity of lead exposure in children. Environ Health Perspect 1996;104:306-312.

Gwiazda R, Campbell C, Smith D: A noninvasive isotopic approach to estimate the bone lead contribution to blood in children: implication for assessing the efficacy of lead abatement. Environ Health Perspect 2005;113:104.

Haavikko K, Anttila A, Helle A, Vuori E. Lead concentrations of enamel and dentine of deciduous teeth of children from two Finnish towns. Arch Environ Health 1984;39:78-84.

Hernández-Avila $\mathrm{M}, \mathrm{Hu} \mathrm{H}$. Decrease in birth weight in relation to maternal bone-lead burden. Pediatrics 1997; 100:856-62.

$\mathrm{Hu} H$, Rabinowitz M, Smith D. Bone lead as a biological marker in epidemiologic studies of chronic toxicity: conceptual paradigms. Environ Health Perspect 1998;106:1-8.

Hu H, Shih R, Rothemberg S, Schwartz BS. The epidemiology of lead toxicity in Adults: measuring dose and consideration of other methodologic issues. Environ Health Persp 2007;115(3):455-62.

Jaffe EK, Volin M, Bronson-Mullins CR, Dunbrack RL, Kervinen J, Martins J, Quinlan JF, Sazinsky MH, Steinhouse EM, Yeung AT: An artificial gene for human 
porphobilinogen Synthase allows comparison of an allelic variation implicated in susceptibility to lead poisoning. J Biol Chem 2000; 275 - 2619.

Järup L. Hazards of heavy metal contamination. Britsh Medical Bulletin 2003;68:167182.

Johann M, Vega-Dienstmaier JM, Salinas-Piélago JE, Gutiérrez-Campos MR, Mandamiento-Ayquipa RD, Yara-Hokama MC, Ponce-Canchihuamán J Castro-Morales J. Lead levels and cognitive abilities in Peruvian children. Níveis de chumbo e funções cognitivas em crianças Peruanas. Rev Bras Psiquiatr 2006;28(1):33-9.

Johnston MV, Goldstein GW. Selective vulnerability of the developing brain to lead. Curr Opin Neurol 1998; 11(6): 689-93.

Lamadrid-Figueroa H, Téllez-Rojo MM, Hernández-Avila M, Trejo-Valdivia B, SolanoGonzález M, Mercado-Garcia A et al. Association between the plasma/whole blood lead ratio and history of spontaneous abortion: a nested cross-sectional study. BMC Pregnancy Childbirth 2007; 7:22.

Lanphear BP, Dietrich K, Auinger P, Cox C. Cognitive deficits associated with blood lead concentrations $<10 \mu / \mathrm{dL}$ in US children and adolescents. Public Health Rep 2000; 115(6): 521-9.

Lanphear BP, Hornung R, Khoury J, Yolton K, Baghurst P, Bellinger DC, et al. Lowlevel environmental lead exposure and children's intellectual function: an international pooled analysis. Environ Health Perspect. 2005;113:894-99.

Lanphear BP, Matte TD, Rogers J, Clickner RP, Dietz B, Bornschein RL et al. The contribution of lead-contaminated house dust and residential soil to children's blood lead levels. A pooled analysis of 12 epidemiologic studies. Environ Res 1998; 79(1): 51-68.

Lappalainen $\mathrm{R}$, Knuuttila $\mathrm{M}$. The distribution and accumulation of $\mathrm{Cd}, \mathrm{Zn}, \mathrm{Pb}, \mathrm{Cu}, \mathrm{Co}$, $\mathrm{Ni}, \mathrm{Mn}$ and $\mathrm{K}$ in human teeth from five different geological areas of Finland. Arch Oral Biol 1979; 24(5): 363-8.

Lazzari E P. Dental Biochemistry. Lea and Keliger, Philadelphia 1976;7-8. Lead still linger. Disponível em: http://www.cfsan.fda.gov/ dms/fdalead.html.

Leggett RW. An age-specific kinetic model of lead metabolism in humans. Environ Health Perspect 1993; 101(7): 598-616.

Lidsky TI, Schneider JS. Autism and Autistic Symptons Associated with Childhood lead Poisoning. The Journal of Applied Research 2005; 5(1):80-87.

Lidsky TI, Schneider JS. Lead neurotoxicity in children: basic mechanisms and clinical correlates. Brain 2003; 126:5-19.

Mahram M, Mousavinasab N, Dinmohammadi H, Soroush S, Sarkhosh F. Effect of living in lead mining area on growth. Indian J Pediatr 2007;74:555-9 
Major RH. Some landmarks in the historyof lead poisoning. Ann Med Hist 1931;3: 218-27.

Manuais de Legislação Atlas: Segurança e Medicina do Trabalho, vol. 16 (ed 36). São Paulo, Editora São Paulo Atlas, 1997.

McMichael AJ, Baghurst PA, Wigg NR, Vimpani GV, Robertson EF, Roberts RJ. Port Pirie Cohort Study: environmental exposure to lead and children's abilities at the age of four years. N Engl J Med 1988; 319(8): 468-75.

Montenegro MF, Barbosa F Jr, Sandrim VC, Gerlach RF, Tanus-Santos JE. Ethnicity affects the distribution of delta-aminolevulinic acid dehydratase (ALAD) genetic variants. Clin Chim Acta 2006a;367:192-5.

Montenegro MF, Barbosa F Jr, Sandrim VC, Gerlach RF, Tanus-Santos JE. A polymorphism in the delta-aminolevulinic acid dehydratase gene modifies plasma/whole blood lead ratio. Arch Toxicol. 2006b; 80(7): 394-8.

Mudipalli A. Lead hepatotoxicity \& potential health effects. Indian J Med Res 2007; 126:518-27.

Muldoon SB, Cauley JA, Kuller LH, Morrow L, Needleman HL, Scott J, Hooper FJ. Effects of blood lead levels on cognitive function of older women. Neuroepidemiology 1996; 15(2): 62-72.

Needleman H L, Gunnoe C, Leviton A, Reed R, Peresie H, Maher C, Barrett P. Deficits in psychologic and classroom performance of children with elevated dentine lead levels. N Engl J Med 1979;300:689-695.

Needleman $\mathrm{HL}$, Bellinger $\mathrm{D}$. The health effects of low level exposure to lead. Annu Rev Public Health 1991;12:111-140.

Needleman HL, Davidson I, Sewell EM, Shapiro IM. Subclinical lead exposure in philadelphia schoolchildren. Identification by dentine lead analysis. N Engl J Med 1974; 290:245-248.

Needleman HL, Gatsonis CA. Low-level lead exposure and the IQ of children: a metaanalysis of modern studies. JAMA 1990; 263:673-678.

Needleman HL, McFarland C, Ness RB, Fienberg SE, Tobin MJ. Bone lead levels in adjudicated delinquents. A case controlstudy. Neurotoxicol Terato 2002;24:711-717.

Needleman HL, Riess JA, Tobin MJ, Biesecker GE, Greenhouse JB.Bone lead levels and delinquent behavior. J Am Med Assoc. 1996;275:363-9.

Needleman HL, Tuncay OC, Shapiro IM. Lead Levels in deciduos teeth of urban and suburban American children. Nature 1972;235:11-112.

Needleman HL. Lead at low dose and the behavior of children. Acta Psychiatr Scand Suppl 1983;303:26-37. 
Needleman HL. Salem comes to the National Institutes of Health: notes from inside te crucible of scientific integrity. Pediatrics 1992;90:977-981.

Nevin R. Understanding international crime trends: The legacy of preschool lead exposure. Environ Res 2007;104:315-36.

Nie $H$, Chettle D, Luo L, O'Meara J. Dosimetry study for a new in vivo X-ray fluorescence (XRF) bone lead measurement system. Nuclear Instr Meth Physics B 2007;225-230.

Nriagu J, Burt B, Linder A, Ismail A, Sohn W. Lead levels in blood and saliva in a lowincome population of Detroit, Michigan. Int J Hyg Environ Health 2006; 209(2):10921.

Nriagu JO: The rise and fall of leaded gasoline. Sci Total Environ 1990; 92:13.

O'Flaherty EJ. Physiologically based models for bone-seeking elements. V. Lead absorption and disposition in childhood. Toxicol Appl Pharmacol. 1995; 131(2): 297308.

Olympio KPK, Gonçalves C, Günther WMR, Bechara EJH. Neurotoxicity and aggressiveness triggered by low-level lead in children: a review. Pan Am J Public Health. 2009;26(3):266-75.

Padula NAMR, Abreu MH, Miyazaki LCY, Tomita N. Intoxicação por chumbo e saúde infantil; ações intersetoriais para o enfrentamento da questão. Cadernos de Saúde Pública 2006;22:163-171.

Paoliello MM, De Capitani E, da Cunha F, Matsuo T, Carvalho MF, Sakuma A, Figueiredo B: Exposure of children to lead and cadmium from mining area of Brazil. Environ Res 2002; 88:120-8.

Paoliello MM, De Capitani EM. Environmental contamination and human exposure to lead in Brazil. Rev Environ Contam Toxicol 2005; 184: 59-96.

Papanikolaou NC, Hatzidaki EG, Belivanis S, Tzanakakis GN, Tsatsakis AM Lead toxicity update. A brief review. Med Sci Monit 2005;11:329-36.

Parsons PJ, Reilly AA, Esernio-Jenssen D. Screening children exposed to lead: an assessment of the capillary blood lead fingerstick test. Clin Chem 1997:43:302-311.

Parsons PJ, Reilly AA, Hussain A. Observational study of erythrocyte protoporphyrin screening test for detecting low lead exposure in children: impact of lowering the blood lead action threshold. Clin Chem. 1991;37(2):216-25.

Parsons PJ, Slavin W. A rapid Zeeman graphite furnace atomic absorption spectrometric method for the determination of lead in blood. Spectrochim Acta B 1993;48:925-39. 
Patrick L. Lead toxicity, a review of the literature. Part 1:Exposure, evaluation, and treatment. Altern Med Rev 2006; 11: 2-22.

Purchase NG, Fergusson JE. Lead in teeth: the influence of the tooth type and the sample within a tooth on lead levels. Sci Total Environ 1986; 52(3): 239-50.

Rabinowitz M B. Relating tooth and blood lead levels in children. Bull Environ Contam Toxicol 1995;55(6):853-7.

Rabinowitz M B. Toxicokinetics of bone lead. Environ Health Perspect 1990;91:33-37.

Rabinowitz MB, Leviton A, Bellinger D: Relationships between serial blood lead levels and exfoliated tooth dentin lead levels: models of tooth lead kinetics. Calcif Tissue Int 1993; 53:338.

Rabinowitz MB, Leviton A, Bellinger DC. Blood lead--tooth lead relationship among Boston children.Bull Environ Contam Toxicol 1989;43(4):485-92.

Rabinowitz MB, Wetherill GW, Kopple JD. Kinetic analysis of lead metabolism in healthy humans. J Clin Invest. 1976; 58(2): 260-70.

Rabinowitz MB. Toxicokinetics of bone lead. Environ Health Perspect. 1991;91:33-7.

Rezende VB, Barbosa F Jr, Montenegro MF, Sandrim VC, Gerlach RF, Tanus-Santos JE. Haplotypes of vitamin $D$ receptor modulate the circulating levels of lead in exposed subjects. Arch Toxicol. 2008; 82(1): 29-36.

Rinderknecht $\mathrm{AL}$, Kleinman $\mathrm{MT}$, Ericson JE. Pb enamel biomarker: deposition of preand postnatal $\mathrm{Pb}$ isotope injection in reconstructed time points along rat enamel transect. Environ Res 2005;99:169-176.

Rothenberg SJ, Kondrashov V, Manalo M, Jiang J, Cuellar R, Garcia M, et al. Increases in hypertension and blood pressure during pregnancy with increased bone lead levels. Am J Epidemiol. 2002;156:1079-87.

Rothenberg SJ, Schnaas L, Perroni E, Hernández RM, Martínez S, Hernández C. Preand postnatal lead effect on head circumference: a case for critical periods. Neurotoxicol Teratol 1999;21(1):1-11.

Rust SW, Kumar P, Burgoon DA, Niemuth NA, Schultz BD. Influence of bone-lead stores on the observed effective-ness of lead hazard intervention. Environ Res $1999 ; 81: 175-184$.

Ryan JA, Scheckel KG, Berti WR, Brown SL, Casteel SW, Chaney RL et al. Reducing children's risk from lead in soil. Environ Sci Technol. 2004; 38(1): 18A- 24A.

Saper RB, Phillips RS, Sehgal A, Khouri N, Davis RB, Paquin J et al. Lead, mercury, and arsenic in US- and Indian-Manufactured ayurvedic medicines sold via the internet. J Am Med Assoc. 2008; 300:915-23. 
Satcher DS. The surgeon general on the continuing tragedy of childhood lead poisoning.Public Health Rep 2000;115(6):579-80.

Sathaye AU, Javadekar BB. A presumptive case of lead poisoning in a brass-worker's child. J Indian Med Assoc 2000; 98:457-8.

Schaffner, RM. Lead in canned food. Food Technol 1981;0-4.

Schroeder HA, Tipton IH. The human body burden of lead. Arch Environ Health 1968; 17(6): 965-78.

Schütz A, Bergdahl IA, Ekholm A, Skerfving S. Measurement by ICP-MS of lead in plasma and whole blood of lead workers and controls. Occup Environ Med 1996; 53(11): 736-40.

Schwartz BS, Hu H. Adult lead exposure: time for change. Environ Health Perspect 2007;115(3):451-4.

Schwartz BS, Stewart WF, Bolla KI, Simon PD, Bandeen-Roche K, Gordon PB, et al. Past adult lead exposure is associated with longitudinal decline in cognitive function. Neurology. 2000a; 55(8): 1144-50.

Schwartz J, Landrigan PJ, Baker EL, Orenstein WA, von Lindern IH: Lead-induced anemia: Dose-response relationships and evidence for a threshold. Am J Publ Health $1990 ; 80: 165$.

Segura-Muñoz SI, Trevilato TM, Takayanagui AM, Hering SE, Cupo P. Heavy metals in water of drinking fountains [Article in Spanish] Arch Latinoam Nutr 2003;53:59-64.

Selevan SG, Landrigan PJ, Stern FB, Jones JH. Mortality of lead smelter workers. Am J Epidemiol 1985;122:673-83.

Shapiro IM: The lead content of teeth. Evidence establishing new minimal levels of exposure in a living preindustrial human population. Arch Environ Health 30:483, 1978.

Sierra EM, Tiffany-Castiglioni E. Reduction of glutamine synthetase activity in astroglia exposed in culture to low levels of inorganic lead. Toxicology 1991; 65:295304.

Silbergeld EK, Schwartz J, Mahaffey K. Lead and osteoporosis:mobilization of lead from bone in postmenopausal women Environ Res 1988;47:79-94.

Souza Guerra C. Utilização de dentes decíduos de regiões com diferentes históricos de contaminação ambiental para detecção de grupos de crianças expostas ao chumbo no Brasil [dissertação]. Piracicaba: Faculdade de Odontologia de Piracicaba da Universidade Estadual de Campinas; 2010.

Spínola AG, Fernícola NAGG, Mendes R. Intoxicação profissional por chumbo. In: Medicina do Trabalho - Doenças Profissionais. São Paulo: Sarvier;1988.p. 437-460. 
Stewart D J. Teeth as indicators of exposure of children to lead. Arch Dis Child 1974; 49:895-897.

Stewart WF, Schwartz BS, Simon D, Kelsey K, Tood AC. ApoE genotype, past adult lead exposure, and neurobehavioral function. Environ Health Perspect. 2002;110(5):501-505.

Téllez-Rojo MM, Hernández-Avila $M$, Lamadrid-Figueroa $H$, Smith $D$, HernándezCadena $L$ et al. Impact of bone lead and bone resorption on plasma and whole blood lead levels during pregnancy. Am J Epidemiol 2004; 160:668-78.

Tiffany-Castiglioni E. Cell culture models for lead. Neurotoxicology 1993; 14:513-36.

Tsalev DL, Zaprianov ZK. Lead. In: Atomic absorption spectrometry in occupational and environmental health practice.Florida: CRC Press, p.137-150, 1985.

Tvinnereim HM, Eide R, Riise T: Heavy metals in human primary teeth: some factors influencing the metal concentrations. Sci Total Environ 255:21, 2000.

Uryu T, Yoshinaga J, Yanagisawa Y, Endo M, Takahashi J. Analysis of lead in tooth enamel by laser ablation-inductively coupled plasma-mass spectrometry. Anal Sci 19:1413-1416, 2003.

Warren C. Brush with Death: a social history of lead poisoning. $1^{\text {rd }}$ ed. The Johns Hopkins Paperbacks;2000.

Weidmann SM, Weatherell JA, Hamm SM: Variations of enamel density in sections of human teeth. Arch Oral Biol 12:85, 1967.

White LD, Cory-Slechta DA, Gilbert ME, Tiffany-Castiglioni E, Zawia NH, Virgolini M, Rossi-George A, Lasley SM, Qian YC, Basha MR. New and evolving concepts in the neurotoxicology of lead. Toxicol Appl Pharmacol. 2007; 225:1-27.

Wigg NR: Low-level lead exposure and children. J Paediatr Child Health 37:423, 2001.

World Health Organization: Regional Office for Europe: air quality guidelines. Geneve, Switzerland, World Health Organization, 1986.

Wright JP, Dietrich KN, Ris MD, Hornung RW, Wessel SD, Lanphear BP, Ho M, Rae MN. Association of prenatal and childhood blood lead concentrations with criminal arrests in early adulthood. PLoS Med. 2008; 5(5): e101.

Wright RO, Hu H, Maher TJ, Amarasiriwardena C, Chaiyakul P, Woolf AD, Shannon MW. Effect of iron deficiency anemia on lead distribution after intravenous dosing in rats. Toxicol Ind Health. 1998; 14(4): 547-51.

Wright RO, Shannon MW, Wright RJ, Hu H. Association between iron deficiency and low-level lead poisoning in an urban primary care clinic. Am J Public Health.1999; 89(7): 1049-53. 
Wright RO, Tsaih SW, Schwartz J, Wright RJ, Hu H. Association between iron deficiency and blood lead level in a longitudinal analysis of children followed in an urban primary care clinic. J Pediatr. 2003; 142(1): 9-14.

Ziegler $\mathrm{EE}$, Edwards $\mathrm{BB}$, Jensen $\mathrm{RL}$, Mahaffey $\mathrm{KR}$, Fomon $\mathrm{SJ}$. Absorption and retention of lead by infants. Pediatr Res. 1978; 12(1): 29-34. 


\section{APÊENICE}

Apêndice A - Questionário.

Nome:

Mãe:

Pai:

Código:

Número:

Dente:

1. Idade atual

2. Diagnóstico neurológico da criança

3. Idade gestacional ao nascer

4. O parto da criança foi normal ou cesariana? Prematuro ou a termo?

5. Peso atual e ao nascimento

6. Houve algum período em que a criança teve baixo peso?

7. Durante a gestação houve ingestão de algum medicamento?

8. Durante a infância houve ingestão de algum medicamento?

9. Estatura e peso atual

10. Profissão dos pais e outros trabalhadores da casa durante a gestação

11. Local de nascimento (cidade e bairro)

12. Endereço atual

13. A residência atual é próximo de industrias, fábricas? Quais?

14.E anteriormente? A residência era próximo de industrias, fábricas? Quais? 
15. Morou em região rural onde eram utilizados agrotóxicos?

16. Houve pintura das paredes da casa durante a gestação ou enquanto a criança era muito pequena?

17. Existe algum ferro-velho próximo da sua residência?

18. A criança tem hábito de comer terra?

19. A criança costuma brincar com pilhas?

20. Doenças maternas prévias e durante a gestação

21. A mãe da criança é diabética?

22. Que tipo de água a criança ingere? De abastecimento público? De poço artesiano ou mineral?

23. A criança teve trauma nos dentes? Se sim, quando?

24. Descreva ocorrência, frequência e época em que a criança teve quaisquer distúrbios sistêmicos (febre alta, doenças da infância, influências genéticas)?

25. Número de pessoas na casa

26. Diagnóstico principal do problema principal da criança 
27. Atualmente:

a. Apanha objetos?

b. Leva à boca? Se sim, é muito ou pouco freqüente? Que tipo de objetos?

c. Anda sem apoio?

d. Tem boa compreensão da linguagem?

e. Fala?

f. Frequenta escola?

g. Doenças intercorrentes até o momento (Nome, dose e períodos em que utilizou)

h. Alimentação via oral (independente ou não?) ou sonda (tipo e tempo de uso) 


\title{
ANEXOS
}

Anexo A

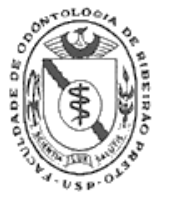

UNIVERSIDADE DE SÃO PAULO

FACULDADE DE ODONTOLOGIA DE RIBEIRÃO PRETO

COMITÊ DE ÉTICA EM PESQUISA

Avenida do Café, $s / n^{\circ}$ - Telefone: (016) 3602-3963

14040-904 - Ribeirão Prets - SP - Brasil

OF.CEP/336/FORP

Fax: (016) 3633-0999

Ribeirão Preto, 28 de agosto de 2009.

Senhora Professora,

Ref.: Processo $n^{\circ} 2008.1 .324 .58 .1$

CAAE $n^{\circ} 0029.0 .138 .000-08$

A pedido da Profa. Dra. Cláudia Helena Lovato da Silva, Coordenadora do Comitê de Ética em Pesquisa, desta Faculdade, informamos que o referido Comitê em sua $101^{\text {a }}$ Sessão, realizada em 20 de agosto de 2009, aprovou o Relatório Parcial do Projeto de Pesquisa: "Concentração de chumbo em dentes de crianças com alterações neurológicas e controles".

$\mathrm{Na}$ oportunidade, lembramos da necessidade de entregar na Secretaria do Comitê, com o formulário preenchido pelo pesquisador responsável, os Relatórios Parciais no dia 30 de maio de 2010 e 30 de maio de 2011 e o Relatório Final no dia 30 de maio de 2012.

Atenciosamente,

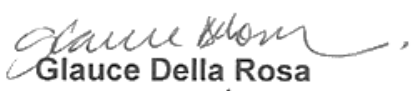

Secretária do Comitê de Ética em Pesquisa

\author{
À Senhora \\ Profa. Dra. RAQUEL FERNANDA GERLACH \\ Departamento de Morfologia, Estomatologia e Fisiologia - FORP/USP \\ GDR//rnm
}


Anexo B.

\title{
TERMO DE CONSENTIMENTO LIVRE E ESCLARECIDO
}

\begin{abstract}
Os pesquisadores responsáveis por este projeto convidam
estudo"Concentração de chumbo em dentes de crianças com alterações neurológica e controles". Assino este termo de consentimento livre e esclarecido como responsável pela criança sendo___ (pai, mãe, avó, guardião, etc), e desta forma autorizo que o menor sob minha responsabilidade participe da pesquisa.

Justificativa: A contaminação por chumbo pode fazer muito mal às crianças e por isso o interesse em descobrir se as crianças com problemas neurológicos atendidas em APAEs foram expostas durante os primeiros anos de vida à quantidades reais altas e chumbo do que as crianças sem problemas neurológicos. Objetivo: Descobrir se as crianças co problema s neurológicos e que estão em atendimento nas APAEs tềm maior quantidade de chumbo nos dentes do que crianças sem problemas neurológicos. Procedimentos: No início do trabalho, os pais e as crianças serão convidados a guardar dentinhos de leite que forem perdidos naturalmente pela criança durante o estudo. Todas as crianças perdem 20 dentes de leite a partir de 5 anos de idade. No lugar destes dentes de leite nascem os dentes permanentes. Os dentes de leite guardados pelos pais poderão ser usados no estudo, para realizar testes para ver quanto chumbo tem dentro do dentinho de cada criança. Desconfortos: Ostestes de esmalte não causam nenhum desconforto para a criança. São procedimentos extremamente rápidos e absolutamente indolores de forma que não será feito anestesia.Riscos: Não haverá utilização de qualquer tipo de procedimento que traga risco aos participantes. Benefícios: esta pesquisa tratá informações importantes para a comunidade sobre contaminação por chumbo. Métodos alternativos: um método alternativo para saber da exposição de crianças ao chumbo é a dosagem no sangue, mas este método NÃO será utilizado

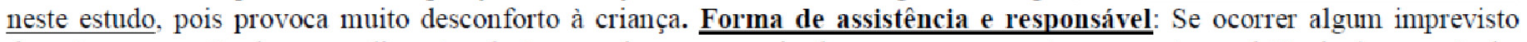
durante a execução dos procedimentos desta pesquisa, os pesquisadores se comprometem a prestar assistência (responsáveis: Profa Dra. Raquel Fernanda Gerlach e CD.Carolina de Souza Guerra- Avenida do Café, S/N - Departamento de Morfologia, Estomatologia e Fisiologia - Faculdade de Odontologia de Ribeirão Preto - Tel: 9119-3418). Esclarecimentos antes e durante a pesquisa sobre a metodologia: Se houver qualquer dúvida não esclarecida neste documento, o pai/mãe/responsável poderá procurar a CD. Carolina de Souza Guerra ou a Profa Raquel Fernanda Gerlach, nos telefones indicados para maiores esclarecimentos. Liberdade de recusar ou retirar o consentimento sem penalizacão: para fazer parte do estudo, a criança deverá estar com o termo de consentimento livre e esclarecido assinado e com vontade de doar o(s) dente(s) havendo plena liberdade para a criança deixar de participar da pesquisa em qualquer momento, sem que esta decisão implique em qualquer prejuizo para a criança. Garantia de sigilo e privacidade: esta pesquisa é cientifica e poderá ser publicada em jornais, revistas e/ou congressos cientificos no país e no exterior, mantendo-se o sigilo e respeitando-se o código de Defesa do Menor e dó Adolescente. Não está previsto o ressarcimento de despesas, uma vez que os sujeitos da pesquisa só doarão seus dentes mediante o consentimento dos pais/responsáveis e sem nenhum custo adicional. Não está prevista qualquer forma de indenizacão referente a possíveis danos, visto que não existe essa possibilidade por se tratar somente de coleta de dentes deciduos esfoliados, sem riscos à saúde.

Estou ciente de que esta pesquisa tem como responsáveis as Profa. Dra. Raquel Fernanda Gerlach (rfgerlach@ forp.usp.br; $3602-$ 4065), a CD. Carolina de Souza Guerra (carolforpusp@hotmail.com; 3602-4014), além dos pesquisadores: Prof Dr ${ }^{\mathrm{a}}$. Maria Cristina Borsatto (FORP-USP), Prof Dra ${ }^{a}$. Kranya Vitória Diaz Serrano (FORP-USP), Prof Dr $^{\mathrm{a}}$.Carolina Araújo Rodrigues Funayama(FMRPUSP), Prof. D.João Moteiro de Pina Neto(FMRP-USP).
\end{abstract}

Assino este documento de livre e espontânea vontade, estando ciente do seu conteúdo. de de 200

Assinatura do pai/mãe/responsável

Prof" Dra. Raquel F. Gerlach (assinatura, nome e CPF)

CD. Carolina de Souza Guerra (assinatura e CPF)

Prof Dr. $^{a}$ Maria Cristina Borsatto (assinatura e CPF)

Prof" Dr. Kranya Vitória Diaz Serrano (assinatura e CPF)

Prof ${ }^{a}$ Dr $^{a}$ Carolina Araújo Rodrigues Funayama (assinatura e CPF)

Prof. D.João Moteiro de Pina Neto (assinatura e CPF) 


\section{Autorização para Reprodução}

Autorizo a reprodução e divulgação total ou parcial deste trabalho, por qualquer meio convencional ou eletrônico, para fins de estudo e pesquisa, desde que citada a fonte.

Regina Aparecida Segatto Saiani

Universidade de São Paulo

Faculdade de Odontologia de Ribeirão Preto

Departamento de Clínica Infantil, Odontologia Preventiva e Social

Ribeirão Preto/Fevereiro 2012

Avenida do Café, s/n CEP 14040-904

reginasaiani@usp.br 